\title{
Review Article \\ Matrix Metalloproteinases in Inflammatory Bowel Disease: An Update
}

\author{
Shane O'Sullivan, John F. Gilmer, and Carlos Medina \\ School of Pharmacy and Pharmaceutical Sciences, Trinity College, Dublin, Ireland \\ Correspondence should be addressed to Carlos Medina; carlos.medina@tcd.ie
}

Received 4 July 2014; Accepted 7 September 2014

Academic Editor: H. Barbaros Oral

Copyright (C) 2015 Shane O’Sullivan et al. This is an open access article distributed under the Creative Commons Attribution License, which permits unrestricted use, distribution, and reproduction in any medium, provided the original work is properly cited.

\begin{abstract}
Matrix metalloproteinases (MMPs) are known to be upregulated in inflammatory bowel disease (IBD) and other inflammatory conditions, but while their involvement is clear, their role in many settings has yet to be determined. Studies of the involvement of MMPs in IBD since 2006 have revealed an array of immune and stromal cells which release the proteases in response to inflammatory cytokines and growth factors. Through digestion of the extracellular matrix and cleavage of bioactive proteins, a huge diversity of roles have been revealed for the MMPs in IBD, where they have been shown to regulate epithelial barrier function, immune response, angiogenesis, fibrosis, and wound healing. For this reason, MMPs have been recognised as potential biomarkers for disease activity in IBD and inhibition remains a huge area of interest. This review describes new roles of MMPs in the pathophysiology of IBD and suggests future directions for the development of treatment strategies in this condition.
\end{abstract}

\section{Introduction}

Inflammatory bowel disease (IBD) which includes both ulcerative colitis (UC) and Crohn's disease (CD) is a chronic and relapsing autoimmune disease characterised by inflammation of the gastrointestinal tract. The estimated mean prevalence of IBD in western countries is 1 in 1,000 [1,2] and although data are less available for the developing world, incidence of the disease is rising globally $[3,4]$. Both idiopathic forms of the disease share common symptoms of abdominal pain, diarrhoea, rectal bleeding, and fever. Ulcerative colitis is characterised by continuous inflammation involving the rectum and colon which extends proximally. Crypt abscesses from infiltration of neutrophils and ulceration of the mucosa is observed. Crohn's disease may affect any region of the gastrointestinal tract intermittently with the terminal ileum being the most common. The inflammatory process may extend through the intestinal wall narrowing the intestinal lumen and is histologically characterized by the formation of granulomas, fibrosis, and fistulae $[5,6]$.

The human matrix metalloproteinases (MMPs) are a family of 24 zinc dependent endopeptidases. They are grouped by domain structure and substrate preference into collagenases, gelatinases, stromelysins, and membrane type MMPs (MTMMPs) [7]. The subgroups of MMPs have distinct structural domains but all possess a conserved catalytic domain with a $\mathrm{Zn}^{2+}$ at the active site and a prodomain which confers latency. The family of proteases were first studied for their ability to degrade the extracellular matrix and basement membrane to facilitate cell migration, infiltration, and tissue remodelling. As our understanding of MMPs has grown, they have been recognised as key regulators of cell function through their ability to cleave a vast range of cytokines, chemokines, receptors, proteases, and adhesion molecules to alter their function $[8,9]$. MMPs are regulated at several levels from transcription, translation, secretion, and activation. There is also a large list of physiological inhibitors of MMPs which serve to regulate MMP activity and proteolysis. The four tissue inhibitors of MMPs (TIMPs) are specific inhibitors of MMPs that reversibly inhibit the MMPs in a 1:1 stoichiometric fashion.

These enzymes have long been linked with IBD and their role in intestinal inflammation was reviewed by Medina and 
Radomski in 2006 [5]. Our current understanding of the aetiology of IBD is that genetic susceptibilities in gut barrier integrity and innate and adaptive immune response can lead to an inappropriate inflammatory reaction in response to bacteria in the gut or other environmental factors $[10,11]$. It is in this context that we review the recent evidence for the role of MMPs in the disease.

\section{Association between MMPs and IBD: Enzymes Involved and Cellular Source}

Most MMPs are transcriptionally upregulated in response to proinflammatory cytokines, cell-cell, or cell-ECM interactions [12]. The collagenases (MMP-1, -8, and -13), gelatinases (MMP-2 and -9), stromelysins (MMP-3 and -10), matrilysin (MMP-7), and macrophage elastase (MMP-12) are the most studied in the context of IBD. The wide range of cellular sources, which has been known to include epithelial cells, mesenchymal cells, and leukocytes, has been reinforced in recent studies. Myofibroblasts are now recognised as playing an active role in intestinal inflammation and the pathogenesis of IBD. These stromal cells have been shown to secrete MMP-2 and, upon stimulation, MMP-1, -3 and -9 [13-15]. Human colonic epithelium was shown to produce increased amounts of MMP-1, $-3,-7,-9,-10$, and -12 in IBD patients [16] and mucosal biopsies from UC patients identified vascular endothelial cells and infiltrating leukocytes as the major sources of MMP-7 and -13 [17]. Infiltrating macrophages were seen to be a major source of MMP-8, -9, and -10 in human IBD and a mouse model of colitis $[18,19]$ and isolated IgG plasma cells from IBD patients were shown to produce high and sustained amounts of MMP-3 [20]. Neutrophils are also major contributors of MMP-9 in intestinal inflammation where it is stored in granules and can be released upon stimulation $[18,21]$.

The range of cell types that secrete MMPs during intestinal inflammation reflects their integral involvement in the pathogenesis of IBD. Several studies from the previous decade have suggested a role for MMPs in IBD by showing their transcriptional upregulation and increased activity during active inflammation in the gut. The evidence for the involvement of MMPs in human IBD is unequivocal and recent reports further describe instances, pattern of expression, and cellular sources of the MMPs.

Transcripts or protein levels of MMP-1, -2, -3, -7, -9, -10, -12 , and -13 are demonstrated to be upregulated in inflamed IBD mucosa or serum of IBD patients and MMP proteolytic activity was increased in cells from inflamed IBD epithelium [16, 22-25]. Gene expression profiling showed that MMP1 was upregulated in UC and CD and linked to HIF-1 mediated inflammation. MMP-3 and -7 were upregulated in UC and MMP-7 was associated with genes known to regulate angiogenesis [26, 27]. Other studies have focused on the involvement of groups or individual MMPs in IBD or models of colitis.

2.1. Gelatinases (MMP-2, -9). MMP-9 mucosal expression and protein levels, as well as serum antigen levels were significantly higher in UC patients compared to controls and these levels corresponded to the severity of the disease. Interestingly, these trends were not replicated in lymphocytic colitis or collagenous colitis where MMP-9 does not seem to contribute to the severity of the disease [28]. Gene expression profiling combined with qPCR has shown the upregulation of MMP-2 in paediatric CD [29]. This enzyme was also shown to be upregulated in a rat TNBS-induced colitis model and corresponded with the severity of the disease [30] which is in agreement with earlier studies [31,32]. A murine DSS induced colitis model showed increased gelatinase mRNA levels in the colon [33]. Furthermore, patients with ischaemic colitis show increased gelatinase expression in inflamed areas compared with noninflamed areas or control patients implicating them in inflammation [34] and gelatinase-double knockout mice were protected from DSS, TNBS, or Salmonella typhimurium induced colitis [35].

2.2. Stromelysins (MMP-3, -10). The expression of MMP-3 has been shown to be significantly upregulated in inflamed areas of colons of IBD patients compared to uninflamed areas implicating its involvement in the inflammatory process [36]. In addition, increased expression of epithelial MMP-10 and stromal TIMP-3 has been found in both UC and CD paediatric patients compared to non-IBD patients [37]. The stromelysins were deemed to be the greatest contributors to DSS induced colitis in one study and their inhibition with siRNA or blocking of the signalling pathways leading to their upregulation resulted in an amelioration of colitis [38].

2.3. Collagenases (MMP-1, -8, -13). MMP-1 has been shown to be upregulated in ulcerated and inflamed areas of colon mucosa of UC patients and its expression correlates with severity of inflammation [39]. MMP-1 and TIMP-1 plasma and colonic mRNA levels are increased in UC correlate with disease severity [40]. Expression is also greater in the inflamed areas of colons in UC patients and MMP-1/TIMP-1 ratio is a measure of inflammation [41]. A group studying the $\mathrm{Na}^{+} / \mathrm{H}^{+}$exchanger (NHE3) discovered that $\mathrm{NHE}^{-/-}$mice developed spontaneous colitis restricted to the mucosa of the distal colon with a concomitant 15-fold increase in MMP-8 expression [42]. MMP-13 has also shown to be present in the inflamed areas of colon in IBD patients but absent in noninflamed colons or in acute diverticulitis and MMP-13 expression correlated with histological measures of disease [43].

2.4. Macrophage Elastase (MMP-12). MMP-12 was also shown to be upregulated in IBD patients as well as Tcell mediated model of colitis and contribute to epithelial degradation and MMP-12 $2^{-/}$mice were protected against TNBS induced colitis [44]. Epithelial and stromal MMP-12 along with MMP-3 and -7 have been also upregulated in pouch mucosa of paediatric onset UC, suggesting that the expression of MMPs paediatric UC pouch in the long-term shares characteristics with IBD [45]. 


\section{Genetic Basis of IBD: MMP Polymorphisms}

Susceptibility to the development of IBD is associated with polymorphisms in genes coding for elements of the immune system or epithelial barrier. First degree relatives of IBD patients have an increased relative risk of up to tenfold compared with background population [46-48]. NOD2 (CARD15/IBD1) has been identified as a susceptibility gene for $C D$ which can affect host interaction with LPS and trigger NF- $\kappa$ B signalling [49-51]. Several large genome wide studies have identified loci that are linked to IBD; 16q12 (IBD1), 12q13 (IBD2), 6p21 (IBD3), 14q11 (IBD4), 19p13 (IBD5), 5q31-q33 (IBD6), and Xq21.3 [52-57] and polymorphisms of genes other than NOD2 have been identified as conferring susceptibility including IL23R and ATG16L1 [58-60]. Given the recognised involvement of MMPs in IBD and the strong genetic component of the disease, several groups have investigated the associations between known MMP polymorphisms and IBD phenotypes.

An extensive study of MMP-1, -2, -3, -7, -8, -9, -10, $-12,-13$, and -14 and TIMP-1, -3 , and -4 single nucleotide polymorphisms (SNPs) in UC, carried out in a New Zealand cohort, found that SNPs in MMP-3, MMP-8, MMP-10, and MMP-14 were associated with the disease [61]. The study was able to make associations with some of the SNPs and disease phenotype but the associations made with UC were not replicated in a Dutch cohort. Primary sclerosing cholangitis (PSC) is a cholestatic liver disease characterised by chronic inflammation and fibrosis. It is believed to share pathologies with IBD and $50-80 \%$ of PSC patients also suffer from IBD [62]. Polymorphisms of the MMP-3 gene have been associated with PSC and with UC where the mechanisms are likely to be the same but have yet to be determined [63-65]. An MMP-3 SNP has also been associated with increased risk of stenosing behaviour in CD [66]. Preliminary studies have shown associations between collagenous colitis and an MMP9 SNP but not MMP-1 or MMP-7 SNPs [67]. Two different TIMP-1 SNPs were associated with increased susceptibility to CD [66].

\section{Role of Bacteria in IBD: Interactions with MMPs}

There is a body of evidence to suggest that gut microbes are the key to the initiation and development of IBD. It is likely that the disease is triggered by interaction of the gut microflora with host defences following impaired barrier function. Antibiotics or some probiotics have shown to be of benefit in treating IBD $[68,69]$. Further evidence for the role of bacteria in triggering the disease is that gnotobiotic mice do not develop colitis but it rapidly emerges when normal luminal flora are reintroduced $[70,71]$ and that experimental colitis can be induced in mice in response to adherentinvasive E. coli, strains of Salmonella [72] or Helicobacter $[73,74]$.

Much interest has been generated over the years in specific species of bacteria which may be causative agents for IBD. Mycobacterium avium paratuberculosis (MAP) has sparked much recent debate regarding its involvement in Crohn's disease and is the subject of numerous reviews and meta-analyses [75-84]. The subspecies is the causative agent of Johne's disease, an inflammatory disease mainly in ruminants with similarities to $\mathrm{CD}$ such as diarrhoea, leukocyte infiltration to the intestinal wall, and intestinal lesions. Indeed, MAP has been shown to be present in a higher percentage of IBD patients than healthy controls; however, the associations have not proven to be conclusive $[77,80]$. MAP infection is associated with an upregulation of MMPs in cattle and it upregulates MMPs in cultured murine macrophages [85-87]. A recent study examined the expression of MMPs in UC patients who tested positive for MAP DNA but found it no different to patients without MAP DNA [88]. In contrast to this, another group showed that mice given oral MAP had increased colonic expression of MMP-2, $-9,-13$, and -14 as well as TIMP-1 in response to the bacteria [89].

A combination of the antibiotic minocycline and the probiotic E. coli Nissle 1917 was shown to improve recovery form DSS induced colitis in mice including improved ratio of beneficial/harmful bacteria and reduced MMP-9 expression [90]. However, no experiments were carried out to discern the antibiotic effects of minocycline from its MMP inhibitory and immunomodulatory effects in reference to the protective effect observed. A group studying Citrobacter rodentiuminduced colitis in mice found that MMP-9 was upregulated in the model. While epithelial barrier integrity and histopathological observations were unchanged between $\mathrm{MMP}^{-9^{-/-}}$and wild type mice, increased IL-17 expression was observed in the MMP- $9^{-/-}$mice. Interestingly, the gut microbiome was altered in wild type mice following infection but not in MMP$9^{-/-}$mice, implicating a role for MMP-9 in the depletion of microbial diversity in the gut, after infection [91]. MMP7 can also modulate the gut microbiome where it has been shown to cleave the inactive alpha-defensin, procryptdins, to their active form [92]. Cryptdin- 4 is mostly active against noncommensal bacteria; however, its reduced form, which is inactivated by MMP-7, demonstrates greater bacteriocidal activity against commensal gut bacteria [93].

Interestingly, direct antibacterial effects for MMP-12 have been demonstrated as it can disrupt bacterial cell membranes in the macrophage phagosome [94].

\section{Recent Pathways Regulating MMPs in IBD}

MMPs are regulated at several levels from transcription to enzyme activation. The interconnectedness of inflammatory networks including activation of signal transduction pathways, where release of a cytokine can trigger an inflammatory cascade, or indeed the protease web where activation of a proenzyme can in turn lead to the activation of a host of other enzymes and their targets, makes delineation difficult. Despite decades of study, the place and role of MMPs in this network is still under investigation and here we summarize the recent studies of the place of MMPs in this network in IBD (Figure 1). 

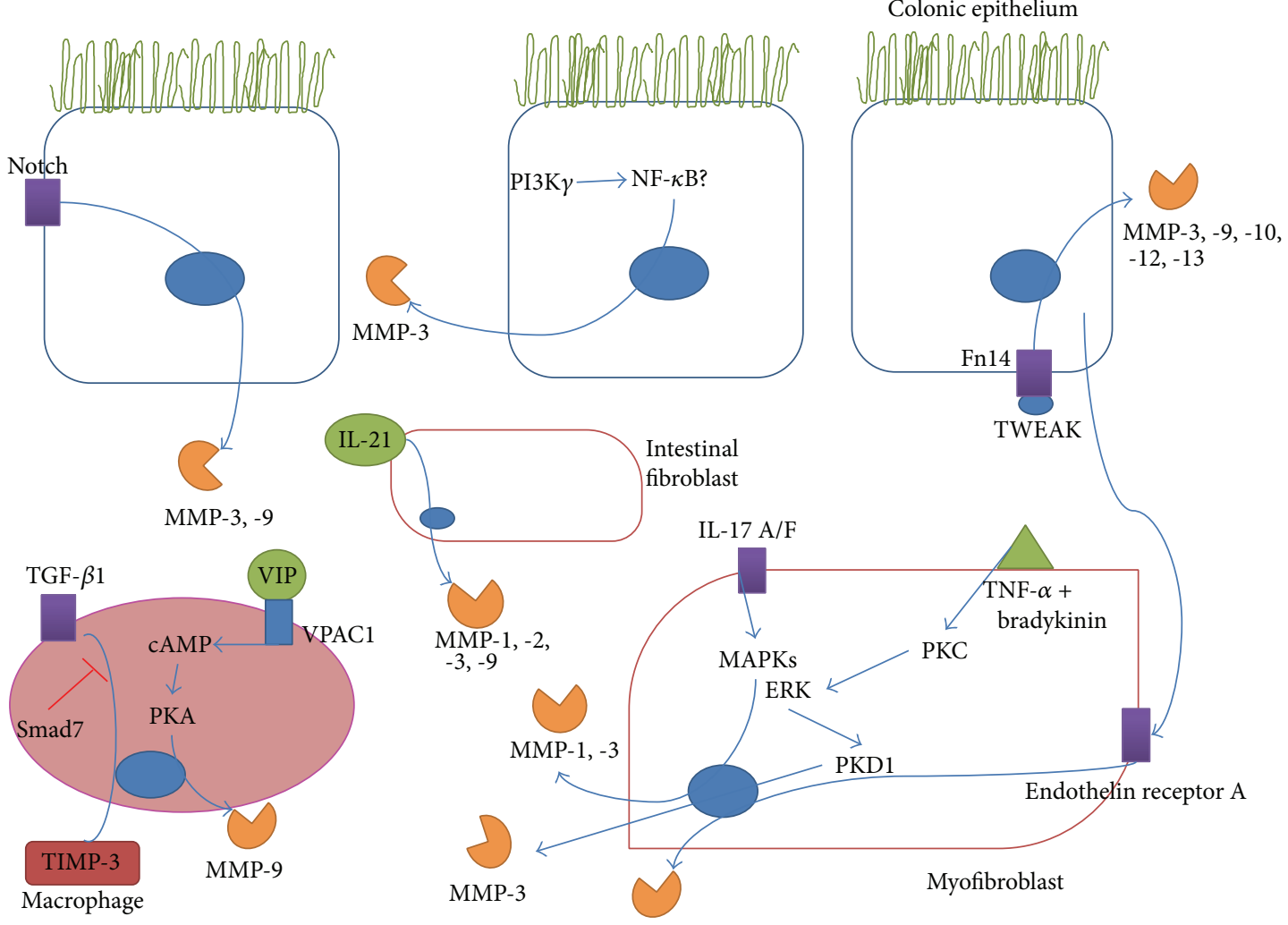

MMP-3

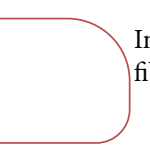

Intestinal

fibroblast
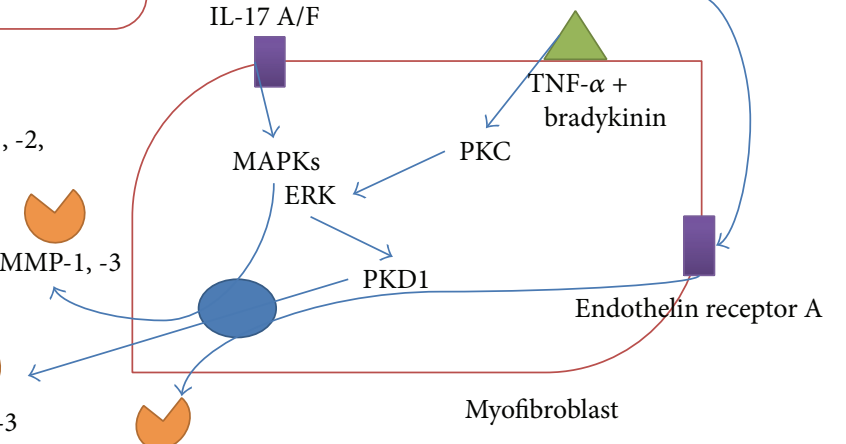

MAPKs

MMP-9

FIGURE 1: Recently described signalling pathways in the gut leading to the upregulation of MMPs in IBD or models of colitis. The various mediators whose interaction with receptors on colonic epithelial cells, intestinal fibroblasts, myofibroblasts, and macrophages can trigger signal transduction pathways leading to increased expression of MMPs or TIMPs are shown. PI3K $\gamma$ (phosphatidylinositol-3 kinase $\gamma$ ), NF- $\kappa \mathrm{B}$ (nuclear factor $\kappa \mathrm{B}$ ), TWEAK (TNF-related weak inducer of apoptosis), TGF- $\beta$ (tissue growth factor $\beta$ ), cAMP (cyclic adenosine monophosphate), PKA (protein kinase A), VIP (vasoactive intestinal peptide), VPAC1 (vasoactive intestinal peptide receptor 1), MAPKs (mitogen activated protein kinases), ERK (extracellular signal-regulated kinase), PKC (protein kinase C), PKD (protein kinase D), and IL (interleukin).

Some of these studies have shown new inducers of MMPs in IBD. IL-17A and IL-17F can increase secretion of MMP1 and -3 in subepithelial myofibroblasts and also enhance the actions of IL- $1 \beta$ and TNF- $\alpha$ on these MMPs in a MAPK mediated manner [95]. IL-21 was also shown to play a part in the upregulation of MMP-1, -2, -3 , and -9 in intestinal fibroblasts without an increase in TIMPs [96]. TNF-like weak inducer of apoptosis (TWEAK) is a member of the TNFfamily of cytokines that signals through its receptor, fibroblast growth factor-inducible molecule 14 (Fn14). Inhibition of the TWEAK pathway resulted in reduced severity of TNBS induced colitis in mice resulting in reduced expression of MMP-3, $-9,-10,-12$, and -13 along with other inflammatory mediators [97].

Other recent studies have characterised various new signalling pathways involved in the transcriptional upregulation of MMPs in intestinal inflammation. For example, inhibition of Notch signalling reduces MMP-3 and -9 expression in DSS induced colitis [98]. A recent study showed that inhibition of PI3K $\gamma$ had anti-inflammatory effects in TNBS induced colitis which resulted in increased Treg response and decreased NF$\kappa \mathrm{B}$ mediated expression of MMP-9 and other inflammatory mediators [99]. VPAC1, a receptor for vasoactive intestinal peptide (VIP), enhances DSS induced colitis through activation of PKA and increased MMP-9 expression, among other mediators [100]. Colonic myofibroblasts were shown to produce MMP-3 in response to bradykinin and TNF$\alpha$ through a pathway that involved activation of PKC and ERK, establishing a critical role for the downstream PKD1 [15]. A study investigating the crosstalk between subepithelial myofibroblasts and colonic epithelial cells found that the myofibroblasts produced MMP-9 in response to the cytokines TNF- $\alpha$, IL- $1 \beta$, and TGF- $\beta$ but was inhibited by IFN- $\gamma$. Interestingly, incubation of the myofibroblasts with media containing the releasate of cytokine stimulated epithelial cells resulted in an upregulation of MMP-9 which was mediated by endothelin receptor A signalling [14]. TGF- $\beta 1$ was shown to protect against TNBS induced colitis in mice through upregulation of TIMP-3 in lamina propria mononuclear cells. Knock-down of Smad7, the TGF- $\beta 1$ receptor antagonist, resulted in increased TIMP-3 expression [101]. Chymase has been shown to be a relevant activator of pro-MMP-9 in DSS induced colitis [102]. In a study on the effects of mast cell tryptase in IBD, MMP-3, -9, and -13 were downregulated in DSS treated mast cell protease (MCP) $6 / 7^{-/-}$mice compared to wild type DSS treated showing a regulation of these MMPs 
TABLE 1: Recently described roles for MMPs in IBD.

\begin{tabular}{llcc}
\hline MMP & Role in IBD & Reference \\
\hline MMP-1 & Prevention of fibrosis & {$[145]$} \\
MMP-2 & $\begin{array}{l}\text { Generation of antiangiogenic factors, maintenance of epithelial barrier function, } \\
\text { and prevention of fibrosis }\end{array}$ & {$[119,135,145]$} \\
MMP-3 & Generation of endostatin & {$[118]$} & {$[105,106,118]$} \\
MMP-7 & $\begin{array}{l}\alpha \text {-defensin activation, chemokine expression, wound healing, and generation of } \\
\text { endostatin }\end{array}$ & {$[18]$} \\
MMP-8 & Neutrophil infiltration & {$[18,107,118,119,125,134,145]$} \\
& Chemokine expression, neutrophil infiltration, generation of anti-angiogenic & {$[19]$} \\
MMP-9 & factors, VEGF-A processing, decreased goblet cell differentiation, and prevention of & {$[111,118]$} \\
MMP-10 & fibrosis & Wound healing, & {$[118]$} \\
MMP-13 & Activation of TNF- $\alpha$ and generation of endostatin & \\
MMP-20 & Generation of endostatin &
\end{tabular}

by the proteases [103]. All these studies contribute to our understanding of the signalling pathways involved in MMP regulation in IBD.

\section{New Evidence for Functions of MMPs in IBD}

As stated previously, the view of MMPs as simple ECM proteases is vastly oversimplified. MMPs can activate or inhibit a wide range of cytokines, chemokines, receptors, adhesion molecules and signalling molecules in order to regulate local inflammation in the gut and new roles are being discovered continually (Figure 2). Here we review the recent literature concerning MMP action in intestinal inflammation beyond ECM degradation. A summary is provided in Table 1.

6.1. MMPs in the Immune Response. The $\alpha$-defensins, which modulate IL-1 $\beta$, are cleaved and activated by MMP-7 [104]. MMP- $7^{-/-}$mice were more susceptible to DSS induced colitis. MMP-7 is postulated to reduce IL- $1 \beta$ release through activation of $\alpha$-defensins [105]. Another study highlights the dual effect of the protease in colitis where it mediates both tissue injury and also healing in DSS induced colitis. MMP- $7^{-/-}$mice had a lower mortality rate and the increased inflammation in the wild type animals was ascribed to increased neutrophil migration through increased expression of the chemokines KC and MIP-2 [106]. Transgenic mice overexpressing epithelial MMP-9 developed worse DSS and ST induced colitis which correlated with an increased expression of KC [107]. An interesting recent study described how $\mathrm{MMP}-10^{-/-}$mice developed a more severe colitis in response to DSS and that MMP-10 derived from macrophages was required for gut healing. Although the mechanisms of this protection were not described, depleted macrophage numbers in the MMP- $10^{-/-}$mice may have prevented colonic healing [19]. Proline-glycine-proline (PGP) is a product of collagen breakdown by propyl endopeptidase (PE) and MMPs and is known to be a chemoattractant for neutrophils [108]. It was recently demonstrated that this is a novel mechanism for MMP induced neutrophil infiltration in
IBD where MMP-8, -9, and PE were upregulated in the inflamed intestines of IBD patients and in mice with DSS induced colitis. Generation of these enzymes resulted in PGP and increased infiltration of neutrophils. PGP neutralisation resulted in decreased neutrophil infiltration and lessened the severity of the colitis [18].

TNF- $\alpha$ is a proinflammatory cytokine whose levels are increased in the blood, colonic mucosa, and stools of IBD patients. It contributes to the pathogenesis of the disease by increasing inflammation through MAPK and NF- $\kappa \mathrm{B}$ activation, increasing cell proliferation and altering epithelial barrier permeability [109]. Anti-TNF therapy has been a major breakthrough in recent years for the treatment of moderate to severe CD and UC refractory to traditional therapies. Upon synthesis, homotrimeric TNF- $\alpha$ migrates to the cell membrane where it is cleaved into the soluble and biologically active form. Until recently, TACE/ADAM17 was believed to be the only relevant in vivo activator of TNF- $\alpha$ [110]; however, MMP-13 has now been demonstrated to perform the same function. Vandenbroucke et al. discovered that the observed effects of MMP-13 on epithelial integrity in DSS induced colitis, such as mucus depletion, intestinal inflammation, and loss of tight junction function were mediated through activation of TNF- $\alpha$ [111]. The significance of this discovery in development of a therapy will remain to be seen.

6.2. MMPs in Angiogenesis. Angiogenesis is now believed to play a major role in the process of chronic inflammation and has been suggested to contribute to the pathology of IBD. Early cytokine, chemokine, and growth factor release facilitate the process which promotes increased leucocyte infiltration. The understanding of angiogenesis in IBD was summarised previously [112]; here we limit ourselves to the more recent studies where MMPs are implicated.

Endothelial cell-produced MMP-1, -3, and -9 are upregulated in human IBD and experimental colitis. These enzymes are potentially involved in different aspects of angiogenesis. MMPs could have dual roles in angiogenesis acting as proangiogenic mediators during tissue remodelling and then as antiangiogenic mediators through generation of angiostatin preventing vessel maturation. At a simplified level, MMPs 


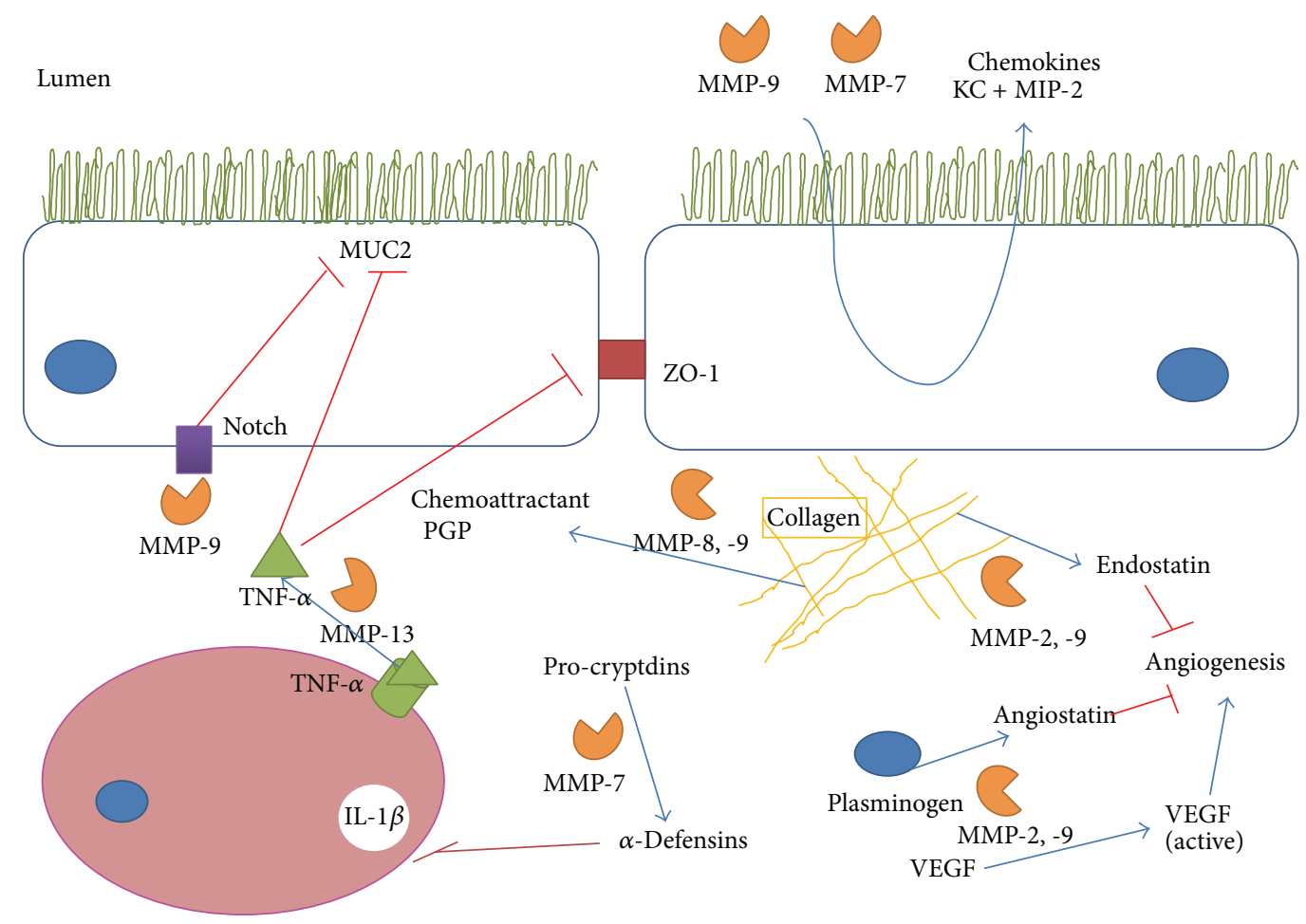

FIGURE 2: Recently described functions for MMPs in IBD. A summary of some of the roles of MMPs in IBD is shown including regulation of epithelial barrier through MUC2 expression and activation of immune response through cleavage of procryptdins, chemokines, and cytokines. MMPs also have a role to play in angiogenesis through allowing migration of endothelial cells and alteration of VEGF but also release of endostatin and angiostatin. MUC2 (mucin 2), KC (CXCL1), MIP-2 (macrophage inflammatory protein 2), ZO-1 (zona occludens protein 1), VEGF (vascular endothelial growth factor), and PGP (proline-glycine-proline).

facilitate angiogenesis through remodelling of the ECM, permitting incorporation of migrating endothelial cells which then form new vessels [113]. While this may be accurate, regulation of angiogenic factors in the gut by MMPs is also likely to contribute. It is known that MMPs can release bound forms of VEGF-A from the ECM, cell membrane, heparin affinity regulatory peptide (HARP), and connective tissue growth factor (CTGF), although the functional relevance of this has been assessed in cancer models and not in IBD [8]. MMP-1 and -3 can cleave heparin-sulfate proteoglycan in endothelial cells to release basic fibroblast growth factor (bFGF) [114] and transforming growth factor- $\beta$ (TGF- $\beta$ ) can also be released and activated by MMPs [115-117]. Further evidence for the roles of MMPs in angiogenesis is reviewed by Rodríguez et al. [8].

Cleavage of collagen XVIII and plasminogen by several MMPs can generate endostatin and angiostatin, respectively, which are both antiangiogenic factors [118]. These antiangiogenic factor levels were upregulated in a rat model of UC. Administration of mesalamine was able to restore the proangiogenic balance by inhibiting gelatinases and thus generation of these fragments [119].

Others argue that increasing VEGF can lead to excessive and pathological angiogenesis in IBD [120-122] and that angiogenesis blockade may even be viable as a therapeutic strategy for reducing disease severity in IBD [123]. In this context, the increasing levels of MMP-9 lead to an increased endostatin concentration and treatment with endostatin in MMP- $9^{-/-}$mice can reduce the severity of colitis [124] indicating a protective role for the enzyme. The ability of MMP-9 to release bound VEGF-A and alter its angiogenic outcome $[125,126]$ was not assessed in the context of IBD in the studies described; however, serum MMP-9 levels were found to correlate with serum VEGF in CD but not UC patients [127]. The studies of the regulation of angiogenesis by MMPs in IBD are limited in scope but provide evidence that many of the discoveries made in cancer and other diseases would also hold true for IBD. The net contribution of the MMPs will depend on the microenvironment and thus the generation of pro- or antiangiogenic factors.

6.3. MMPs and Epithelial Barrier Function. Epithelial barrier integrity is essential in maintaining intestinal homeostasis. Infiltration of luminal contents into the lamina propria triggers a local inflammatory response leading to release of proinflammatory mediators, release of MMPs, and further epithelial degradation and inflammation. Indeed, leaking of bacteria or alarmins into the bloodstream can trigger a systemic response, sepsis, or multiorgan failure [128]. MMPs have been implicated in modulation of the epithelial barrier elsewhere in the body [129-131] and owing to its importance in intestinal inflammation, also in the gut, as discussed below.

When investigating the effect of MMP-9 on the colonic epithelial barrier in a model of colitis, it was found that 
MMP-9 $9^{-/-}$mice had increased goblet cell numbers and increased MUC2 expression. Overexpression of MMP-9 resulted in a decrease in goblet cell differentiation [107] and thus decreased MUC2 expression. This reduction of MUC2 expression reduces the protective mucin barrier and was shown to affect the adherence of Salmonella typhimurium [132]. The tight junction protein claudin-1, which has been previously implicated in colitis associated cancer (CAC) [133], was shown to be involved in epithelial homeostasis. Upregulation of claudin-1 following DSS induced colitis results in an upregulation of MMP-9 which triggered Notch signalling resulting in decreased MUC2 expression through decreased goblet cell differentiation [134]. It was also shown that the gelatinases play opposing roles in intestinal inflammation where MMP-9 can potentiate colitis but MMP-2 participates in maintaining epithelial barrier function to prevent the initiation of colitis [135]. MMP-13 indirectly regulates epithelial barrier function through activation of TNF- $\alpha$. Activation of the cytokine increases intestinal epithelial permeability by mediating the endocytosis of the tight junction protein ZO-1 and reducing MUC2 expression, effects that are absent in MMP-13 ${ }^{-/-}$mice [111].

In a DSS induced model of chronic colitis described previously, wild type animals recovered more quickly and completely from the colitis than MMP- $7^{-/-}$animals which may be due to decreased neutrophil infiltration to the mucosa [106]. MMP-7 was shown to be hugely upregulated in an intestinal epithelial wound healing model and resulted in faster resolution of the wound. Under inflammatory conditions, simulated by addition of TNF- $\alpha$ and IL- $1 \beta$, the expression levels were increased further which delayed wound healing [136]. This observation is likely applicable to many of the MMPs, where physiological roles contribute to the pathology of IBD under inflammatory conditions. Another study showed the ability of MMP-7 to cleave galectin-3 and to reverse its wound healing abilities [137]. The contribution of this effect in vivo is undetermined but adds a further layer of complexity.

6.4. MMPs in Intestinal Inflammation-Induced Fibrosis. Fibrosis is a pathological accumulation of ECM which occurs in the intestine as a consequence of IBD and has been recently reviewed [138]. MMP expression, and the balance between their levels and those of the TIMPs or other inhibitors, is crucial for normal ECM homeostasis. A disruption of this balance may promote fibrosis in the intestine. Despite therapeutic advances in IBD, none prevent or reverse established strictures. In UC, fibrosis will normally affect the mucosa and submucosa whereas in $\mathrm{CD}$, transmural thickening can lead to stricture and require surgery [139]. In humans, TGF$\beta /$ Smad pathway seems to be a major contributor to fibrosis in the gut where it can inhibit MMPs and increase the production of TIMPs in mucosa overlaying strictures and in cultured myofibroblasts $[96,140]$ We have also found that the TGF- $\beta /$ ALK5/Smad pathway participates in the pathogenesis of experimental intestinal fibrosis. Indeed, upregulation of ALK5 and TIMP-1, phosphorylation of Smad2 and Smad3 proteins, and increased intestinal wall collagen deposition were found in anaerobic bacteria- and TNBS-induced colitis [141]. In addition, the antifibrotic effects of glutamine in TNBS induced colitis was partly attributed to abrogation of the overexpression of TGF- $\beta$, phosphorylated Smad3, and TIMP-1 [142].

IL-13 is also said to play a role in fibrosis elsewhere in the body partly through regulation of MMP-1 and TIMP-1 expression $[143,144]$. A recent study showed that the cytokine can inhibit expression of MMP-1, -2 , and -9 in cultured fibroblasts and that MMP-2 synthesis is not coordinately upregulated along with that of collagen in fibrotic CD colons [145]. In a DSS model of chronic colitis, the increased expression of gelatinases was said to protect against fibrosis through collagen degradation which is another protective role for these enzymes [33].

6.5. MMPs in Colitis Associated Cancer. Chronic inflammation plays a critical role in gastrointestinal carcinogenesis. As examples, chronic hepatitis, Barrett's oesophagus and IBD. Indeed, patients suffering from IBD are at higher risk for developing colonic neoplasia than normal population, particularly those with extensive colorectal inflammation (pancolitis) which continues for longer periods of time [146]. Indeed, colorectal cancer accounts for one sixth of all UCrelated deaths [147]. The involvement of MMPs in colorectal cancer and metastasis has been extensively studied [148]. We have also found that MMP-9 upregulation is an early event in the adenoma-carcinoma sequence and, therefore, MMP-9 might be a molecular marker for early colorectal carcinogenesis [149]. However, colitis-associated colorectal cancer (CAC) does not follow an adenoma-carcinoma sequence which is initially associated with genomic instability and the concomitant loss of key tumour suppressor genes. In contrast, CAC shows an inflammation-dysplasia-carcinoma sequence, in which a p53 mutation plays a key role in the early stage and later the APC function is diminished [150]. The p53 functions as tumour suppressor; therefore, the loss or mutation of p53 could lead to neoplasia formation.

A summary of the role of MMPs in CAC is provided in Figure 3. It is interesting to note that while colitis is mediated by MMP-9, the same enzyme may play a protective role in CAC. In fact, MMP-9 could play dual roles in CAC. It has been shown that MMP- $9^{-/-}$mice are more susceptible to CAC than wild type mice and the protective effect of MMP9 is believed to be mediated through Notch-1 activation and a subsequent decrease in $\beta$-catenin [151]. The same group further investigated these effects and concluded that the upregulation of MMP-9 in colitis leads to activation of Notch-1, increased p53 expression leading to increased levels of $\mathrm{p} 21^{\text {Waf/Cip } 1}$, and members of the Bax family proteins to resulting in cell cycle arrest and apoptosis [152].

In contrast to the protective effects of MMP-9, a mouse model of CAC found that activation of neutrophils by the chemokine CXCL2 induced MMP-9 expression which promoted neovascularization and possibly drove CAC [153]. Where integrin linked kinase (ILK) has been implicated in carcinogenesis, ILK-intestinal epithelial cell knockout mice showed reduced tumour growth and MMP-9 expression in 


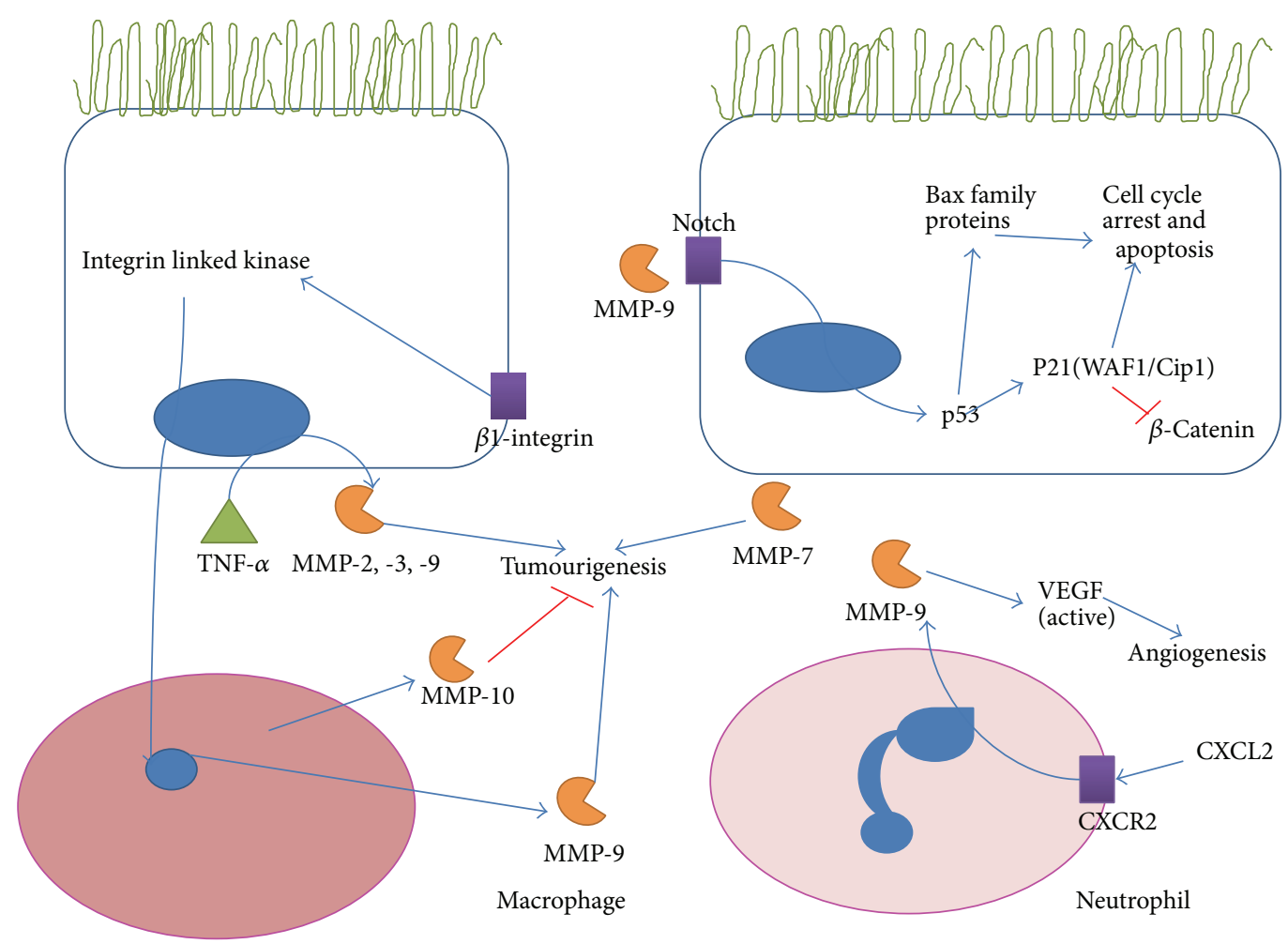

FIGURE 3: MMPs in colitis associated cancer. A summary of the reported involvement of MMPs in colitis associated cancer (CAC) including the dual roles of MMP-9 where it increases apoptosis and cell cycle arrest through notch cleavage and activation of p53 but also promotes tumour growth, partially through activation of vascular endothelial growth factor (VEGF). MMP-7 is upregulated in UC associated dysplasia and MMP-2 and -3 have also been reported to increase tumour growth. MMP-10 from macrophages is believed to inhibit colitis associated cancer based on a knock-out mouse study.

experimentally induced CAC [154]. In addition, it has been also shown that infliximab, an anti-TNF-alpha antibody, could prevent CAC in DSS-induced colitis, an effect which was accompanied by the reduction of MMP-9 and MMP-11 levels [155]. Similar results were observed when omeprazole exerted a proapoptotic effect in a model of CAC and inhibited MMP-9 and -11 and MT1-MMP [156] and celecoxib reduced gelatinase colon levels in models of CAC [157].

Examination of human UC biopsy samples revealed that there was a direct correlation between the expression of MMP-7 and the grade of UC-associated dysplasia or carcinoma [158]. Further study is required to uncover the precise role of the protease in the progression of the disease. On the other hand, MMP-10 seems to play a protective role from CAC development as it has been found that MMP-10-/mice had significantly worse inflammatory scores and also higher propensity for development of dysplastic lesions after DSS exposure [19]. More research is required to discover the expression patterns of specific MMPs at the various stages of CAC, to reveal the roles that the enzymes play and the net contribution to tumorigenesis. This may then facilitate successful targeting of specific enzymes as a treatment.

\section{MMP Inhibition}

Failure of MMP inhibitors (MMPIs) in cancer trials led to a major rethink of the potential of these compounds in the clinic, but we can now reflect on how little was known about the functions of the specific MMPs in a given setting and the clinical effect of inhibition. Early phase I trials revealed unexplained musculoskeletal pain and inflammation which limited the dosage that could be administered. Phase II/III trials examining efficacy, were met with further problems. Owing to the fact that the MMPIs were cytostatic and not cytotoxic, conventional measures of efficacy such as reduction in tumour size were not appropriate. Chosen endpoint measures such as reduction in serum biomarkers were criticized for not necessarily reflecting any reduction in tumour growth and also for being unable to demonstrate MMP inhibition [159]. Ultimately, the trials failed to demonstrate efficacy and several were abandoned. Many researchers now agree that invasive or metastatic cancer may not have been appropriate diseases to trial of the drugs and that preclinical studies suggest the drugs may be more useful in treating earlier stage cancers or inflammatory conditions [160]. A review by Hu et al. covers the history and considers the future for MMP inhibition in the treatment of cancer and inflammation [12]. With continuous studies teasing the physiological from the pathological roles of MMPs in the setting of IBD, we are getting closer to being able to imagine clinical use of an MMPI in IBD. Here we summarise some of the reports of MMP inhibition in intestinal inflammation since 2006 (Table 2). 
TABLE 2: Recently reported MMP inhibitors in models of intestinal inflammation. Novel MMP inhibitors, plant extracts tested in IBD models, and existing IBD therapies are included where MMP-9 expression or activity has been measured.

\begin{tabular}{|c|c|c|c|}
\hline MMP inhibitor & MMPs inhibited & Model & Reference \\
\hline $\mathrm{RO} 28-2653$ & MMP-2, -9 & DSS (mouse) (acute) & [163] \\
\hline Ilomastat & MMP-1 & TNBS (rat) & [173] \\
\hline Minocycline & MMP-2, $-3,-9,-13$ & DSS or TNBS (mouse) & {$[172]$} \\
\hline Etiasa (mesalazine) & MMP-2 & TNBS (rat) & {$[30]$} \\
\hline Irsogladine maleate & MMP-2 & DSS (mouse) & [209] \\
\hline Infliximab & MMP-1, $-2,-3,-9,-13$ & Human CD (serum and biopsy) & {$[174,175]$} \\
\hline CC-10004 & MMP-3 & Mononuclear cells from human CD & {$[165]$} \\
\hline Nitrate-barbiturates & MMP-9 & Cytokine stimulated Caco- 2 cells & {$[161]$} \\
\hline Auraptene & MMP-7, $-2,-9$ & DSS (mouse) & {$[180]$} \\
\hline coumarin 4-methylesculetin & MMP-9 & TNBS (rat) & {$[181]$} \\
\hline Tris(methoxymethoxy)chalcone & MMP-7 & TNF- $\alpha$ stimulated HT-29 cells & [182] \\
\hline Curcumin & MMP-3 & Cultured colonic myofibroblasts from IBD patients & {$[183]$} \\
\hline $\begin{array}{l}\text { Phenylpropanoid glycosides: teupolioside } \\
\text { and verbascoside }\end{array}$ & MMP-2, -9 & DNBS (rat) & {$[184,185]$} \\
\hline Neovastat & MMP-9 & TNBS (rat) & [188] \\
\hline Alpha-lipoic & MMP-9 & DSS (mouse) & {$[210]$} \\
\hline Cordyceps militaris & MMP-3 and -9 & DSS (mouse) & [189] \\
\hline Calcium $\left(\mathrm{CaHPO}_{4}\right)$ & MMP-9, $-10,-13$ & HLA-B27 transgenic rat & {$[190]$} \\
\hline
\end{tabular}

7.1. Synthetic MMP Inhibitors. Various studies have examined the potential of novel small molecule inhibitors of MMPs in animal models of colitis. Barbiturate-nitrate hybrids can inhibit MMP-9 activity partly through their nitric oxide mimetic properties [161]. NO mimetics may have the paradoxical effect of reducing $\mathrm{NO} / \mathrm{iNOS}$ activity through negative feedback, therefore, reducing inflammation and associated MMP-9 release. Our group has recently reviewed the complex interactions of NO and MMP-9 and exploiting these interactions may be therapeutically beneficial in IBD [162]. Integration of a nitrate group as an $\mathrm{NO}$ donor may be a novel approach to enhancing efficacy and reducing sideeffects of small molecule MMP inhibitors. The benefits of the MMPI RO28-2653 in the DSS model were attributed to its gelatinase selectivity. In particular, ability to spare MMP-1 and -7 reduced the side-effects observed with broad spectrum inhibition and efficacy was comparable to that of doxycycline [163]. Novel synthetic curcuminoid pyrazole derivatives inhibit MMP-9 activity in TNF- $\alpha$ and IL- $1 \beta$ stimulated Caco-2 cells [164]. Sequestration of MMP-2 by hydroxamate beads can inhibit MMP-2 activity and prevented disruption of the epithelial barrier in an in vitro model and is an interesting approach to MMP inhibition at the membrane [129]. The thalidomide analogue, CC-10004, was shown to reduce TNF- $\alpha$ and MMP-3 levels from mononuclear cells isolated from the lamina of CD patients [165].

Vitamin D has inherent immunomodulatory properties and synthetic analogues reduce hypercalcaemia. One such compound, ZK156979, has been shown to be effective in preventing TNBS induced colitis [166] and was shown to inhibit gelatinase activity in cultured peripheral mononuclear cells from healthy and IBD patients [167]. ZK191784 is an intestine specific vitamin $\mathrm{D}$ analogue which can exert an antiinflammatory effect without causing hypercalcaemia [168170]. This compound and calcitriol were tested in cultured colon biopsies of healthy and IBD patients and were found to reduce MMP-2, -3 , and -9 levels as well as the adhesion molecules ICAM-1 and MAdCAM-1 [171].

Several studies have tested known MMPIs in models of human IBD or assessed the ability of therapeutics used in IBD to inhibit MMPs. The tetracycline antibiotics have long been known for their anti-inflammatory properties and for their ability to inhibit MMP expression. Minocycline was shown to reduced inflammation in DSS or TNBS models by reducing the expression of iNOS, proinflammatory cytokines, and MMP-2, -3, -9, and -13 [172] with greater benefit seen in DSS induced colitis when it is combined with the probiotic E. coli Nissle 1917 [90]. The first generation hydroxamate MMPI ilomastat was shown to protect rats from TNBS induced colitis by inhibiting MMP-1 expression in the colon [173]. Slow release granules of mesalazine were able to reduce MMP-2 expression and inflammation [30]. A novel mechanism was described for 5-ASA in angiogenesis during UC where inhibition of TNF- $\alpha$ and gelatinase levels, reduced the levels of angiostatin and endostatin [119].

The effects of the clinically used infliximab on gelatinase levels in CD patients were examined and found that MMP9 serum levels were consistently decreased following infliximab treatments and MMP-9 expressing polymorphonuclear 
leukocytes were also reduced in biopsy samples [174]. MMP3 and -12 were decreased following 10 weeks of infliximab treatment in $\mathrm{CD}$ patients that were responders to the treatment [175]. Using mucosal explants of IBD and control patients, infliximab was shown to downregulate MMP-1, -3, and -9 levels as well as reducing their increase in response to pokeweed mitogen in a genotype dependent manner following analysis of TNF, MMP, and TIMP SNPs [176]. It has also been shown that infliximab could reduce the incidence of tumour development through reduction of MMP-9 and -11 in DSS-induced colitis [155]. Treatment of CD patients with anti-TNF therapy (infliximab or adalimumab) or with corticosteroids and other immunosuppressives (methotrexate or azathioprine) resulted in a decrease of epithelial MMP7 and stromal MMP-9 and -26 and TIMP-1 and -3 [177]. In a similar study, the same group showed results in paediatric IBD where glucocorticoid therapy reduced serum MMP-7, TIMP-1, and MMP-7/TIMP-2 and anti-TNF therapy reduced MMP-7 but to a lesser extent. Interestingly, MMP-8 and -9 levels were not statistically significantly altered [178]. A larger study used microarrays to measure the mucosal expression of 24 MMPs along with TIMPs, ADAM(T)s, and growth factors. Most MMP expression was increased in IBD patients with the exception of MMP-28 which was downregulated and responders to infliximab had a gene expression and gelatinase activity was restored to control levels following treatment [179].

7.2. Natural Products. Research is increasing in the field of natural products as medicines and many of these have been directed towards MMP inhibition in intestinal inflammation.

The coumarin, auraptene, is found in several citrus fruits and has been shown to inhibit MMP-7 activity following DSS induced colitis [180]. The naturally occurring coumarin, 4-methylesculetin, showed comparable effects to sulphasalazine and prednisolone in TNBS induced colitis where it was able to inhibit MMP-9 [181]. 2', $4^{\prime}, 6^{\prime}$ Tris (methoxymethoxy) chalcone (TMMC) protected against TNBS induced colitis and was able to inhibit MMP-7 upregulation induced by TNF- $\alpha$ in HT-29 cells [182]. Curcumin is a component of turmeric with known anti-inflammatory properties and one group investigating its use in IBD showed that it could reduce MMP-3 among other mediators in ex vivo cultured colonic myofibroblasts from IBD patients [183]. PPGs and verbascoside were shown to reduce inflammation, pro-inflammatory signalling and gelatinase expression in DNBS induced colitis $[184,185]$. Neovastat, a product found in shark cartilage, is a known inhibitor of MMPs and angiogenesis and has undergone clinical trials for the treatment of renal carcinoma and plaque psoriasis $[186,187]$. More recently, this agent has shown to inhibit intestinal inflammation in TNBS induced colitis through inhibition of gelatinase expression [188]. Cordyceps militaris is a traditional medicine widely used in East Asia to treat inflammatory conditions and has been shown to inhibit disease activity, along with iNOS and MMP-3 and -9 expression in a DSS induced model of colitis [189]. Calcium supplementation has shown benefit in reducing epithelial permeability and inflammation in the intestine through reduced expression of MMP-9, -10, and -13 in HLA-B27 transgenic rat model of colitis [190].

The pineal gland product melatonin is a known scavenger of free radicals and has anti-inflammatory effects in experimental colitis [191]. In certain instances, NO and peroxynitrite can modulate MMP-9 expression and activity [162] and it is likely that the antioxidant properties of melatonin could reduce colon gelatinase expression in DNBS induced colitis [192]. Further investigation shows that it can mediate NF$\kappa \mathrm{B}$, STAT-3, IL-17, Cox-2, nuclear erythroid 2-related factor 2, connective tissue growth factor, and MMP-9 [193] and its contribution to IBD has been summarised recently [194].

Endogenous fatty acids are known gelatinase inhibitors [195] and polyunsaturated fatty acids were recently shown to be anti-inflammatory in the gut through decreased Cox2 and MMP-9 expression [196]. Orally administered docosahexaenoic acid had comparable efficacy to sulfasalazine in DSS induced colitis but with stronger inhibition of MMP-3, -10 , and -13 [197].

\section{MMPs as Biomarkers for IBD}

The association of MMPs with IBD is now widely accepted. MMP expression or protein levels are now a standard readout for inflammation in the experimental models described previously. There is an unmet need for additional biomarkers to assess the progression of the disease or identification of flares without the need for invasive, time consuming, or expensive imaging techniques. Here we review the recent studies regarding the potential and usefulness of MMPs as markers for inflammation in IBD.

Faecal MMP-9 levels were reported to correlate with the overall Mayo and endoscopic scores, serum CRP, and faecal calprotectin levels in UC patients [198]. As a biomarker, faecal MMP-9 also has potential in recognising severity of pouchitis and, to a lesser extent, CD where correlation with the SES (simple endoscopic score) CD was not statistically significant but overall correlations were better than calprotectin [199]. However, neither faecal calprotectin nor faecal MMP-9 can differentiate between Clostridium difficile induced and a natural relapse in IBD [200].

Serum MMP-9 correlates with disease activity in UC and CD and levels were found to be higher in UC. As a result, this may aid in differentiation between UC and CD where serum MMP-9 was more effective than CRP levels [127]. Neutrophil secreted MMP-9 is often complexed with NGAL and circulating levels of NGAL or NGAL/MMP9 complex have been associated with breast cancer [21] and kidney disease [201]. This complex has recently been described as a potential biomarker for mucosal healing in UC where infliximab reduced serum levels, predictive of mucosal healing [202]. Immunohistochemical staining of colonic biopsy samples for paediatric onset UC patients showed that MMP-9 levels correlated with the histological measures of inflammation but not with any other marker of disease [203]. Urinary gelatinase levels have also been found to be independent predictors of IBD in paediatric patients 
[204] and MMP-3 and MMP-9 serum levels were found to be potentially useful diagnostics of disease activity in children with UC [205].

A gene expression approach was used to assess differences between responders and nonresponders to corticosteroid treatment in severe paediatric UC. MMP-8 was strongly upregulated in nonresponders compared to those patients who had responded to treatment. This effect was believed to be due to the inhibitory effect of methylprednisolone on IL-8, a known inducer of MMP-8 [206].

Microarrays were used to assess the potential of biomarkers in peripheral blood as diagnostic indicators for IBD. MMP-9 was found to be upregulated in IBD patients which corresponded to the combined epithelial and lamina expression in biopsy samples. MMP-9 was identified in this study as one of the top 5 peripheral blood transcripts which could be used in combination to diagnose UC or CD [207]. A large study investigated useful and appropriate biomarkers in IBD and their correlation with the Mayo score in UC or with the ileocolonoscopy (ICO), computed tomography enterography (CTE), or combined ICO-CTE score in CD patients as measures of inflammation. The study concluded that combined faecal calprotectin and serum MMP-9 best predicted inflammation in UC and combination of faecal calprotectin, serum MMP-9, and serum IL-22 best correlated with ICO-CTE score in CD [208].

The expression pattern of the TIMPs often mirrors that of the MMPs and so the level of inflammation. Several studies have investigated the potential of also measuring TIMP levels as readouts of inflammation severity. MMP-1 and TIMP1 are well known to be upregulated in UC and colonic expression was found to correlate with disease severity. The fact that plasma levels of these proteins correlated well with the mucosal expression was of potential clinical interest [40]. The intestinal expression of MMPs and TIMPs in CD patients was measured before and following immunosuppressive treatment and found that the histological score correlated positively with neutrophil MMP-9, MMP-26, and macrophage TIMP-1. Calprotectin levels followed a similar trend to expression of stromal MMP-26, TIMP-1, and -3. Crohn's disease endoscopic index of severity (CDEIS) value correlated positively with macrophage TIMP-1 and stromal TIMP-3 and negatively with epithelial TIMP-3 which also negatively correlated with C-reactive protein values (CRP) [177]. The levels of MMPs and TIMPs were measured by immunohistochemistry only, and neither serum nor plasma levels were assesed. In paediatric IBD, serum MMP-7 mirrors the disease activity and, together with TIMP-1 expression, is a measure of response to glucocorticoid therapy but to a lesser extent, anti-TNF therapy [178].

\section{Concluding Remarks}

Following recognition of the limited understanding of the MMPs in earlier trials, the field has grown enormously to discover more roles for the proteases. The fact that the expression and activity of the MMPs is upregulated in colitis and IBD has been confirmed through numerous animal model experiments and analysis of IBD patient biopsies. This has led to significant research into the use of MMPs as biomarkers for the severity of inflammation in the colon where results appear promising.

More studies continue to identify the primary cellular sources of the MMPs in the colon and triggers of their transcriptional upregulation or activation. A definitive understanding of cell types and signals involved in MMP upregulating will allow us to target the pathologically upregulated enzymes.

It is clear from the range of MMP substrates and degradomic experiments that the functions of MMPs in IBD go far beyond the simple digestion of ECM proteins. In recent years, more and more studies highlight the role of MMPs in regulation of the immune response through activation or inhibition of cytokines and chemokines, for example, the activation of TNF- $\alpha$ which is exciting given the established role of this cytokine in the pathogenesis of IBD [110]. MMPs have the ability to regulate both proand antiangiogenic factors which may contribute to the pathogenesis of IBD or mucosal healing. The proteases have a similar role in epithelial homeostasis through control of tight junction proteins, goblet cell differentiation and degradation of ECM proteins. These studies are vital to understand the contribution of specific MMPs to a range of processes that make up IBD. However, the potential to therapeutically exploit these discoveries raises several questions. Paramount to the discussion of MMP inhibition is the potential knock on effect of the inhibition. Blocking a single enzyme will affect activation of other proteases and its considerable list of substrates which is likely to disrupt physiological processes. Delineating these activation pathways, completing substrate lists, and understanding the contexts where upregulation of the protease is pathological will remain relevant questions before MMP inhibition becomes a therapeutic option in the clinic. Therefore, while new functions emerge for the MMPs, it will be crucial to understand the setting where an MMP is promoting or inhibiting wound healing, proor antiangiogenic, or inhibiting or amplifying the immune response. As answers to these questions emerge, we can be more confident that targeted inhibition of the MMPs could be of benefit in treating IBD.

\section{Conflict of Interests}

The authors declare that there is no conflict of interests regarding the publication of this paper.

\section{References}

[1] D. C. Baumgart, C. N. Bernstein, Z. Abbas et al., "IBD Around the world: comparing the epidemiology, diagnosis, and treatment: proceedings of the World Digestive Health Day 2010inflammatory bowel disease task force meeting," Inflammatory Bowel Diseases, vol. 17, no. 2, pp. 639-644, 2011.

[2] J. Cosnes, S. Cattan, A. Blain et al., "Long-term evolution of disease behavior of Crohn's disease," Inflammatory Bowel Diseases, vol. 8, no. 4, pp. 244-250, 2002. 
[3] N. A. Molodecky, I. S. Soon, D. M. Rabi et al., "Increasing incidence and prevalence of the inflammatory bowel diseases with time, based on systematic review," Gastroenterology, vol. 142, no. 1, pp. 46.e42-54.e42, 2012.

[4] M. Ravikumara and B. K. Sandhu, "Epidemiology of inflammatory bowel diseases in childhood," Indian Journal of Pediatrics, vol. 73, no. 8, pp. 717-721, 2006.

[5] C. Medina and M. W. Radomski, "Role of matrix metalloproteinases in intestinal inflammation," Journal of Pharmacology and Experimental Therapeutics, vol. 318, no. 3, pp. 933-938, 2006.

[6] R. J. Xavier and D. K. Podolsky, "Unravelling the pathogenesis of inflammatory bowel disease," Nature, vol. 448, no. 7152, pp. 427-434, 2007.

[7] M. Egeblad and Z. Werb, "New functions for the matrix metalloproteinases in cancer progression," Nature Reviews Cancer, vol. 2, no. 3, pp. 161-174, 2002.

[8] D. Rodríguez, C. J. Morrison, and C. M. Overall, "Matrix metalloproteinases: what do they not do? New substrates and biological roles identified by murine models and proteomics," Biochimica et Biophysica Acta, vol. 1803, no. 1, pp. 39-54, 2010.

[9] M. D. Sternlicht and Z. Werb, "How matrix metalloproteinases regulate cell behavior," Annual Review of Cell and Developmental Biology, vol. 17, pp. 463-516, 2001.

[10] D. K. Podolsky, "The current future understanding of inflammatory bowel disease," Bailliere's Best Practice and Research in Clinical Gastroenterology, vol. 16, no. 6, pp. 933-943, 2002.

[11] A. D. Kostic, R. J. Xavier, and D. Gevers, "The microbiome in inflammatory bowel disease: current status and the future ahead," Gastroenterology, vol. 146, no. 6, pp. 1489-1499, 2014.

[12] J. Hu, P. E. Van den Steen, Q.-X. A. Sang, and G. Opdenakker, "Matrix metalloproteinase inhibitors as therapy for inflammatory and vascular diseases," Nature Reviews Drug Discovery, vol. 6, no. 6, pp. 480-498, 2007.

[13] A. Andoh, S. Bamba, M. Brittan, Y. Fujiyama, and N. A. Wright, "Role of intestinal subepithelial myofibroblasts in inflammation and regenerative response in the gut," Pharmacology \& Therapeutics, vol. 114, no. 1, pp. 94-106, 2007.

[14] I. Drygiannakis, V. Valatas, O. Sfakianaki et al., "Proinflammatory cytokines induce crosstalk between colonic epithelial cells and subepithelial myofibroblasts: implication in intestinal fibrosis," Journal of Crohn's and Colitis, vol. 7, no. 4, pp. 286-300, 2013.

[15] J. Yoo, C. E. R. Perez, W. Nie, J. Sinnett-Smith, and E. Rozengurt, "Protein kinase D1 mediates synergistic MMP3 expression induced by TNF- $\alpha$ and bradykinin in human colonic myofibroblasts," Biochemical and Biophysical Research Communications, vol. 413, no. 1, pp. 30-35, 2011.

[16] G. Pedersen, T. Saermark, T. Kirkegaard, and J. Brynskov, "Spontaneous and cytokine induced expression and activity of matrix metalloproteinases in human colonic epithelium," Clinical and Experimental Immunology, vol. 155, no. 2, pp. 257265, 2009.

[17] T. Rath, M. Roderfeld, J. M. Halwe, A. Tschuschner, E. Roeb, and J. Graf, "Cellular sources of MMP-7, MMP-13 and MMP-28 in ulcerative colitis," Scandinavian Journal of Gastroenterology, vol. 45, no. 10, pp. 1186-1196, 2010.

[18] P. J. Koelink, S. A. Overbeek, S. Braber et al., "Collagen degradation and neutrophilic infiltration: a vicious circle in inflammatory bowel disease," Gut, vol. 63, pp. 578-587, 2014.
[19] F. L. Koller, E. A. Dozier, K. T. Nam et al., "Lack of MMP10 exacerbates experimental colitis and promotes development of inflammation-associated colonic dysplasia," Laboratory Investigation, vol. 92, no. 12, pp. 1749-1759, 2012.

[20] J. N. Gordon, K. M. Pickard, A. Di Sabatino et al., "Matrix metalloproteinase-3 production by gut IgG plasma cells in chronic inflammatory bowel disease," Inflammatory Bowel Diseases, vol. 14, no. 2, pp. 195-203, 2008.

[21] J. Vandooren, P. E. van den Steen, and G. Opdenakker, "Biochemistry and molecular biology of gelatinase B or matrix metalloproteinase-9 (MMP-9): the next decade," Critical Reviews in Biochemistry and Molecular Biology, vol. 48, no. 3, pp. 222-272, 2013.

[22] M. J. W. Meijer, M. A. C. Mieremet-Ooms, A. M. van der Zon et al., "Increased mucosal matrix metalloproteinase-1, -2, -3 and -9 activity in patients with inflammatory bowel disease and the relation with Crohn's disease phenotype," Digestive and Liver Disease, vol. 39, no. 8, pp. 733-739, 2007.

[23] G. Lakatos, I. Hritz, M. Z. Varga et al., "The impact of matrix metalloproteinases and their tissue inhibitors in inflammatory bowel diseases," Digestive Diseases, vol. 30, no. 3, pp. 289-295, 2012.

[24] Z. Varga, L. Herszényi, I. Hritz, M. Juhász, P. Miheller, and Z. Tulassay, "The behavior of serum MMP-2, MMP-7, MMP-9, TIMP-1 AND TIMP-2 concentrations in inflammatory bowel diseases," Zeitschrift für Gastroenterologie, vol. 49, p. A93, 2011.

[25] T. Rath, M. Roderfeld, J. Graf et al., "Enhanced expression of MMP-7 and MMP-13 in inflammatory bowel disease: a precancerous potential?" Inflammatory Bowel Diseases, vol. 12, no. 11, pp. 1025-1035, 2006.

[26] L. Gillberg, M. Varsanyi, M. Sjöström, M. Lördal, J. Lindholm, and P. M. Hellström, "Nitric oxide pathway-related gene alterations in inflammatory bowel disease," Scandinavian Journal of Gastroenterology, vol. 47, no. 11, pp. 1283-1297, 2012.

[27] C. L. Noble, A. R. Abbas, J. Cornelius et al., "Regional variation in gene expression in the healthy colon is dysregulated in ulcerative colitis," Gut, vol. 57, no. 10, pp. 1398-1405, 2008.

[28] G. Lakatos, F. Sipos, P. Miheller et al., "The behavior of matrix metalloproteinase-9 in lymphocytic colitis, collagenous colitis and ulcerative colitis," Pathology \& Oncology Research, vol. 18, no. 1, pp. 85-91, 2012.

[29] W. H. Sim, J. Wagner, D. J. Cameron, A. G. Catto-Smith, R. F. Bishop, and C. D. Kirkwood, "Expression profile of genes involved in pathogenesis of pediatric Crohn's disease," Journal of Gastroenterology and Hepatology, vol. 27, no. 6, pp. 1083-1093, 2012.

[30] J.-W. Mao, H.-Y. Tang, X.-Y. Tan, and Y.-D. Wang, "Effect of Etiasa on the expression of matrix metalloproteinase- 2 and tumor necrosis factor- $\alpha$ in a rat model of ulcerative colitis," Molecular Medicine Reports, vol. 6, no. 5, pp. 996-1000, 2012.

[31] M. D. Baugh, M. J. Perry, A. P. Hollander et al., "Matrix metalloproteinase levels are elevated in inflammatory bowel disease," Gastroenterology, vol. 117, no. 4, pp. 814-822, 1999.

[32] K. Matsuno, Y. Adachi, H. Yamamoto et al., "The expression of matrix metalloproteinase matrilysin indicates the degree of inflammation in ulcerative colitis," Journal of Gastroenterology, vol. 38, no. 4, pp. 348-354, 2003.

[33] K. Suzuki, X. Sun, M. Nagata et al., "Analysis of intestinal fibrosis in chronic colitis in mice induced by dextran sulfate sodium," Pathology International, vol. 61, no. 4, pp. 228-238, 2011.

[34] C. Medina, A. Santana, M. C. Paz-Cabrera et al., "Increased activity and expression of gelatinases in ischemic colitis," 
Digestive Diseases and Sciences, vol. 51, no. 12, pp. 2393-2399, 2006.

[35] P. Garg, M. Vijay-Kumar, L. Wang, A. T. Gewirtz, D. Merlin, and S. V. Sitaraman, "Matrix metalloproteinase-9mediated tissue injury overrides the protective effect of matrix metalloproteinase-2 during colitis," American Journal of Physiology: Gastrointestinal and Liver Physiology, vol. 296, no. 2, pp. G175-G184, 2009.

[36] A. J. León, E. Gómez, J. A. Garrote et al., "High levels of proinflammatory cytokines, but not markers of tissue injury, in unaffected intestinal areas from patients with IBD," Mediators of Inflammation, vol. 2009, Article ID 580450, 10 pages, 2009.

[37] L. Mäkitalo, K.-L. Kolho, R. Karikoski, H. Anthoni, and U. Saarialho-Kere, "Expression profiles of matrix metalloproteinases and their inhibitors in colonic inflammation related to pediatric inflammatory bowel disease," Scandinavian Journal of Gastroenterology, vol. 45, no. 7-8, pp. 862-871, 2010.

[38] K. Kobayashi, Y. Arimura, A. Goto et al., "Therapeutic implications of the specific inhibition of causative matrix metalloproteinases in experimental colitis induces by dextran sulphate sodium," Journal of Pathology, vol. 209, no. 3, pp. 376-383, 2006.

[39] Y.-D. Wang and J.-W. Mao, "Expression of matrix metalloproteinase- 1 and tumor necrosis factor- $\alpha$ in ulcerative colitis," World Journal of Gastroenterology, vol. 13, no. 44, pp. 5926-5932, 2007.

[40] Y.-D. Wang, X.-Y. Tan, and K. Zhang, "Correlation of plasma MMP-1 and TIMP-1 levels and the colonic mucosa expressions in patients with ulcerative colitis," Mediators of Inflammation, vol. 2009, Article ID 275072, 5 pages, 2009.

[41] Y.-D. Wang and P.-Y. Yan, "Expression of matrix metalloproteinase-1 and tissue inhibitor of metalloproteinase-1 in ulcerative colitis," World Journal of Gastroenterology, vol. 12, no. 37, pp. 6050-6053, 2006.

[42] D. Laubitz, C. B. Larmonier, A. Bai et al., "Colonic gene expression profile in NHE3-deficient mice: evidence for spontaneous distal colitis," The American Journal of PhysiologyGastrointestinal and Liver Physiology, vol. 295, no. 1, pp. G63G77, 2008.

[43] F. J. Vizoso, L. O. González, M. D. Corte et al., "Collagenase3 (MMP-13) expression by inflamed mucosa in inflammatory bowel disease," Scandinavian Journal of Gastroenterology, vol. 41, no. 9, pp. 1050-1055, 2006.

[44] S. L. Pender, C. K. Li, A. Di Sabatino, T. T. Macdonald, and M. G. Buckley, "Role of macrophage metalloelastase in gut inflammation," Annals of the New York Academy of Sciences, vol. 1072, pp. 386-388, 2006.

[45] L. Mäkitalo, M. Piekkala, M. Ashorn et al., "Matrix metalloproteinases in the restorative proctocolectomy pouch of pediatric ulcerative colitis," World Journal of Gastroenterology, vol. 18, no. 30, pp. 4028-4036, 2012.

[46] M. Orholm, P. Munkholm, E. Langholz, O. Haagen Nielsen, T. I. A. Sorensen, and V. Binder, "Familial occurrence of inflammatory bowel disease," The New England Journal of Medicine, vol. 324, no. 2, pp. 84-88, 1991.

[47] V. Binder and M. Orholm, "Familial occurrence and inheritance studies in inflammatory bowel disease," Netherlands Journal of Medicine, vol. 48, no. 2, pp. 53-56, 1996.

[48] J. B. Park, S.-K. Yang, J.-S. Byeon et al., "Familial occurrence of inflammatory bowel disease in Korea," Inflammatory Bowel Diseases, vol. 12, no. 12, pp. 1146-1151, 2006.
[49] J.-P. Hugot, M. Chamaillard, H. Zouali et al., "Association of NOD2 leucine-rich repeat variants with susceptibility to Crohn's disease," Nature, vol. 411, no. 6837, pp. 599-603, 2001.

[50] J. H. Cho, “The Nod2 gene in Crohn's disease: implications for future research into the genetics and immunology of Crohn's disease," Inflammatory Bowel Diseases, vol. 7, no. 3, pp. 271-275, 2001.

[51] Y. Ogura, D. K. Bonen, N. Inohara et al., "A frameshift mutation in NOD2 associated with susceptibility to Crohn's disease," Nature, vol. 411, no. 6837, pp. 603-606, 2001.

[52] J.-P. Hugot, P. Laurent-Puig, C. Gower-Rousseau et al., "Mapping of a susceptibility locus for Crohn's disease on chromosome 16," Nature, vol. 379, no. 6568, pp. 821-823, 1996.

[53] Y. Ma, J. D. Ohmen, Z. Li et al., "A genome-wide search identifies potential new susceptibility loci for Crohn's disease," Inflammatory Bowel Diseases, vol. 5, no. 4, pp. 271-278, 1999.

[54] J. D. Rioux, M. S. Silverberg, M. J. Daly et al., "Genomewide search in Canadian families with inflammatory bowel disease reveals two novel susceptibility loci," The American Journal of Human Genetics, vol. 66, no. 6, pp. 1863-1870, 2000.

[55] J. Satsangi, M. Parkes, E. Louis et al., "Two stage genome-wide search in inflammatory bowel disease provides evidence for susceptibility loci on chromosomes 3, 7 and 12," Nature Genetics, vol. 14, no. 2, pp. 199-202, 1996.

[56] S. Vermeire, J. Satsangi, M. Peeters et al., "Evidence for inflammatory bowel disease of a susceptibility locus on the $\mathrm{X}$ chromosome," Gastroenterology, vol. 120, no. 4, pp. 834-840, 2001.

[57] H. Yang, S. E. Plevy, K. Taylor et al., "Linkage of Crohn's disease to the major histocompatibility complex region is detected by multiple non-parametric analyses," Gut, vol. 44, no. 4, pp. 519$526,1999$.

[58] R. H. Duerr, K. D. Taylor, S. R. Brant et al., "A genome-wide association study identifies IL23R as an inflammatory bowel disease gene," Science, vol. 314, no. 5804, pp. 1461-1463, 2006.

[59] J. Hampe, A. Franke, P. Rosenstiel et al., "A genome-wide association scan of nonsynonymous SNPs identifies a susceptibility variant for Crohn disease in ATG16L1," Nature Genetics, vol. 39, no. 2, pp. 207-211, 2007.

[60] M. S. Silverberg, R. H. Duerr, S. R. Brant et al., "Refined genomic localization and ethnic differences observed for the IBD5 association with Crohn's disease," European Journal of Human Genetics, vol. 15, no. 3, pp. 328-335, 2007.

[61] A. R. Morgan, D.-Y. Han, W.-J. Lam et al., "Genetic variations in matrix metalloproteinases may be associated with increased risk of ulcerative colitis," Human Immunology, vol. 72, no. 11, pp. 1117-1127, 2011.

[62] T. H. Karlsen, E. Schrumpf, and K. M. Boberg, "Update on primary sclerosing cholangitis," Digestive and Liver Disease, vol. 42, no. 6, pp. 390-400, 2010.

[63] K. Wiencke, A. S. Louka, A. Spurkland, M. Vatn, E. Schrumpf, and K. M. Boberg, "Association of matrix metalloproteinase1 and -3 promoter polymorphisms with clinical subsets of Norwegian primary sclerosing cholangitis patients," Journal of Hepatology, vol. 41, no. 2, pp. 209-214, 2004.

[64] J. Satsangi, R. W. G. Chapman, N. Haldar et al., "A functional polymorphism of the stromelysin gene (MMP-3) influences susceptibility to primary sclerosing cholangitis," Gastroenterology, vol. 121, no. 1, pp. 124-130, 2001.

[65] B. D. Juran, E. J. Atkinson, E. M. Schlicht et al., "Genetic polymorphisms of matrix metalloproteinase 3 in primary sclerosing cholangitis," Liver International, vol. 31, no. 6, pp. 785-791, 2011. 
[66] M. J. W. Meijer, M. A. C. Mieremet-Ooms, R. A. van Hogezand, C. B. H. W. Lamers, D. W. Hommes, and H. W. Verspaget, "Role of matrix metalloproteinase, tissue inhibitor of metalloproteinase and tumor necrosis factor- $\alpha$ single nucleotide gene polymorphisms in inflammatory bowel disease," World Journal of Gastroenterology, vol. 13, no. 21, pp. 2960-2966, 2007.

[67] A. Madisch, S. Hellmig, S. Schreiber, B. Bethke, M. Stolte, and S. Miehlke, "Allelic variation of the matrix metalloproteinase-9 gene is associated with collagenous colitis," Inflammatory Bowel Diseases, vol. 17, no. 11, pp. 2295-2298, 2011.

[68] P. Gionchetti, F. Rizzello, U. Helwig et al., "Prophylaxis of pouchitis onset with probiotic therapy: a double-blind, placebocontrolled trial," Gastroenterology, vol. 124, no. 5, pp. 1202-1209, 2003.

[69] L. Sutherland, J. Singleton, J. Sessions et al., "Double blind, placebo controlled trial of metronidazole in Crohn's disease," Gut, vol. 32, no. 9, pp. 1071-1075, 1991.

[70] C. O. Elson, Y. Cong, V. J. McCracken, R. A. Dimmitt, R. G. Lorenz, and C. T. Weaver, "Experimental models of inflammatory bowel disease reveal innate, adaptive, and regulatory mechanisms of host dialogue with the microbiota," Immunological Reviews, vol. 206, pp. 260-276, 2005.

[71] A. B. Onderdonk, J. A. Hermos, and J. G. Bartlett, "The role of the intestinal microflora in experimental colitis," American Journal of Clinical Nutrition, vol. 30, no. 11, pp. 1819-1825, 1977.

[72] D. Low, D. D. Nguyen, and E. Mizoguchi, "Animal models of ulcerative colitis and their application in drug research," Drug Design, Development and Therapy, vol. 7, pp. 1341-1356, 2013.

[73] A. E. Torrence, T. Brabb, J. L. Viney et al., "Serum biomarkers in a mouse model of bacterial-induced inflammatory bowel disease," Inflammatory Bowel Diseases, vol. 14, no. 4, pp. 480490, 2008.

[74] A. Burich, R. Hershberg, K. Waggie et al., "Helicobacterinduced inflammatory bowel disease in IL-10- and T celldeficient mice," The American Journal of Physiology: Gastrointestinal and Liver Physiology, vol. 281, no. 3, pp. G764-G778, 2001.

[75] W. C. Davis and S. A. Madsen-Bouterse, "Crohn's disease and Mycobacterium avium subsp. paratuberculosis: the need for a study is long overdue," Veterinary Immunology and Immunopathology, vol. 145, no. 1-2, pp. 1-6, 2012.

[76] J. C. Uzoigwe, M. L. Khaitsa, and P. S. Gibbs, "Epidemiological evidence for Mycobacterium avium subspecies paratuberculosis as a cause of Crohn's disease," Epidemiology and Infection, vol. 135, no. 7, pp. 1057-1068, 2007.

[77] K. Over, P. G. Crandall, C. A. O'Bryan, and S. C. Ricke, "Current perspectives on Mycobacterium avium subsp. paratuberculosis, Johne's disease, and Crohn's disease: a review," Critical Reviews in Microbiology, vol. 37, no. 2, pp. 141-156, 2011.

[78] R. Robertson, B. Hill, O. Cerf, K. Jordan, and P. Venter, "A commentary on current perspectives on Mycobacterium avium subsp. paratuberculosis, Johne's disease and Crohn's disease: a review by over et al. (2011)," Critical Reviews in Microbiology, vol. 38, no. 3, pp. 183-184, 2012.

[79] I. Abubakar, D. Myhill, S. H. Aliyu, and P. R. Hunter, "Detection of Mycobacterium avium subspecies paratubercubsis from patients with Crohn's disease using nucleic acid-based techniques: a systematic review and meta-analysis," Inflammatory Bowel Diseases, vol. 14, no. 3, pp. 401-410, 2008.

[80] J. L. Mendoza, R. Lana, and M. Díaz-Rubio, "Mycobacterium avium subspecies paratuberculosis and its relationship with
Cronh's disease," World Journal of Gastroenterology, vol. 15, no. 4, pp. 417-422, 2009.

[81] M. Feller, K. Huwiler, R. Stephan et al., "Mycobacterium avium subspecies paratuberculosis and Crohn's disease: a systematic review and meta-analysis," The Lancet Infectious Diseases, vol. 7, no. 9, pp. 607-613, 2007.

[82] W. Chamberlin, D. Y. Graham, K. Hulten et al., "Review article: Mycobacterium avium subsp. paratuberculosis as one cause of Crohn's disease," Alimentary Pharmacology and Therapeutics, vol. 15, no. 3, pp. 337-346, 2001.

[83] K. Cirone, C. Morsella, M. Romano, and F. Paolicchi, "Mycobacterium avium subsp. paratuberculosis in food and its relationship with Crohn's disease," Revista Argentina de Microbiologia, vol. 39, no. 1, pp. 57-68, 2007.

[84] R. J. Greenstein, "Is Crohn's disease caused by a mycobacterium? Comparisons with leprosy, tuberculosis, and Johne's disease," The Lancet Infectious Diseases, vol. 3, no. 8, pp. 507514, 2003.

[85] P. M. Coussens, C. J. Colvin, G. J. M. Rosa, J. Perez Laspiur, and M. D. Elftman, "Evidence for a novel gene expression program in peripheral blood mononuclear cells from Mycobacterium avium subsp. paratuberculosis-infected cattle," Infection and Immunity, vol. 71, no. 11, pp. 6487-6498, 2003.

[86] P. M. Coussens, C. B. Pudrith, K. Skovgaard et al., "Johne's disease in cattle is associated with enhanced expression of genes encoding IL-5, GATA-3, tissue inhibitors of matrix metalloproteinases 1 and 2, and factors promoting apoptosis in peripheral blood mononuclear cells," Veterinary Immunology and Immunopathology, vol. 105, no. 3-4, pp. 221-234, 2005.

[87] M. Quiding-Järbrink, D. A. Smith, and G. J. Bancroft, "Production of matrix metalloproteinases in response to mycobacterial infection," Infection and Immunity, vol. 69, no. 9, pp. 5661-5670, 2001.

[88] T. Rath, M. Roderfeld, S. Blöcher et al., "Presence of intestinal Mycobacterium avium subspecies paratuberculosis (MAP) DNA is not associated with altered MMP expression in ulcerative colitis," BMC Gastroenterology, vol. 11, article 34, 2011.

[89] M. Roderfeld, A. Koc, T. Rath et al., "Induction of matrix metalloproteinases and TLR2 and 6 in murine colon after oral exposure to Mycobacterium avium subsp. paratuberculosis," Microbes and Infection, vol. 14, no. 6, pp. 545-553, 2012.

[90] N. Garrido-Mesa, P. Utrilla, M. Comalada et al., "The association of minocycline and the probiotic Escherichia coli Nissle 1917 results in an additive beneficial effect in a DSS model of reactivated colitis in mice," Biochemical Pharmacology, vol. 82, no. 12, pp. 1891-1900, 2011.

[91] D. M. Rodrigues, A. J. Sousa, S. P. Hawley et al., "Matrix metalloproteinase 9 contributes to gut microbe homeostasis in a model of infectious colitis," BMC Microbiology, vol. 12, article 105, 2012.

[92] C. S. Weeks, H. Tanabe, J. E. Cummings et al., "Matrix metalloproteinase-7 activation of mouse paneth cell proalpha-defensins: SER43 down arrow ILE44 proteolysis enables membrane-disruptive activity," Journal of Biological Chemistry, vol. 281, no. 39, pp. 28932-28942, 2006.

[93] K. Masuda, N. Sakai, K. Nakamura, S. Yoshioka, and T. Ayabe, "Bactericidal activity of mouse $\alpha$-defensin cryptdin4 predominantly affects noncommensal bacteria," Journal of Innate Immunity, vol. 3, no. 3, pp. 315-326, 2011.

[94] A. M. Houghton, W. O. Hartzell, C. S. Robbins, F. X. GomisRüth, and S. D. Shapiro, "Macrophage elastase kills bacteria 
within murine macrophages," Nature, vol. 460, no. 7255, pp. 637-641, 2009.

[95] Y. Yagi, A. Andoh, O. Inatomi, T. Tsujikawa, and Y. Fujiyama, "Inflammatory responses induced by interleukin-17 family members in human colonic subepithelial myofibroblasts," Journal of Gastroenterology, vol. 42, no. 9, pp. 746-753, 2007.

[96] G. Monteleone, R. Caruso, D. Fina et al., "Control of matrix metalloproteinase production in human intestinal fibroblasts by interleukin 21," Gut, vol. 55, no. 12, pp. 1774-1780, 2006.

[97] T. Dohi, A. Borodovsky, P. Wu et al., “TWEAK/Fn14 pathway: a nonredundant role in intestinal damage in mice through a TWEAK/intestinal epithelial cell axis," Gastroenterology, vol. 136, no. 3, pp. 912.e8-923.e8, 2009.

[98] M. Shinoda, M. Shin-Ya, Y. Naito et al., "Early-stage blocking of Notch signaling inhibits the depletion of goblet cells in dextran sodium sulfate-induced colitis in mice," Journal of Gastroenterology, vol. 45, no. 6, pp. 608-617, 2010.

[99] R. C. Dutra, M. Cola, D. F. P. Leite et al., "Inhibitor of PI3K $\gamma$ ameliorates TNBS-induced colitis in mice by affecting the functional activity of $\mathrm{CD} 4{ }^{+} \mathrm{CD} 25^{+} \mathrm{FoxP}^{+}$regulatory $\mathrm{T}$ cells," British Journal of Pharmacology, vol. 163, no. 2, pp. 358-374, 2011.

[100] M. Yadav, M.-C. Huang, and E. J. Goetzl, "VPAC1 (vasoactive intestinal peptide (VIP) receptor type 1) G protein-coupled receptor mediation of VIP enhancement of murine experimental colitis," Cellular Immunology, vol. 267, no. 2, pp. 124-132, 2011.

[101] I. Monteleone, M. Federici, M. Sarra et al., “Tissue inhibitor of metalloproteinase- 3 regulates inflammation in human and mouse intestine," Gastroenterology, vol. 143, no. 5, pp. 1277.e41287.e4, 2012.

[102] K. Ishida, S. Takai, M. Murano et al., "Role of chymasedependent matrix metalloproteinase- 9 activation in mice with dextran sodium sulfate-induced colitis," Journal of Pharmacology and Experimental Therapeutics, vol. 324, no. 2, pp. 422-426, 2008.

[103] M. J. Hamilton, M. J. Sinnamon, G. D. Lyng et al., "Essential role for mast cell tryptase in acute experimental colitis," Proceedings of the National Academy of Sciences of the United States of America, vol. 108, no. 1, pp. 290-295, 2011.

[104] Y. Shirafuji, H. Tanabe, D. P. Satchell, A. Henschen-Edman, C. L. Wilson, and A. J. Ouellette, "Structural determinants of procryptdin recognition and cleavage by matrix metalloproteinase7," The Journal of Biological Chemistry, vol. 278, no. 10, pp. 79107919, 2003.

[105] J. Shi, S. Aono, W. Lu et al., "A novel role for defensins in intestinal homeostasis: regulation of IL- $1 \beta$ secretion," Journal of Immunology, vol. 179, no. 2, pp. 1245-1253, 2007.

[106] M. Swee, C. L. Wilson, Y. Wang, J. K. McGuire, and W. C. Parks, "Matrix metalloproteinase-7 (matrilysin) controls neutrophil egress by generating chemokine gradients," Journal of Leukocyte Biology, vol. 83, no. 6, pp. 1404-1412, 2008.

[107] H. Liu, N. R. Patel, L. Walter, S. Ingersoll, S. V. Sitaraman, and P. Garg, "Constitutive expression of MMP9 in intestinal epithelium worsens murine acute colitis and is associated with increased levels of proinflammatory cytokine Kc," American Journal of Physiology: Gastrointestinal and Liver Physiology, vol. 304, no. 9, pp. G793-G803, 2013.

[108] A. Gaggar, P. L. Jackson, B. D. Noerager et al., "A novel proteolytic cascade generates an extracellular matrix-derived chemoattractant in Chronic neutrophilic inflammation," Journal of Immunology, vol. 180, no. 8, pp. 5662-5669, 2008.
[109] J. Pedersen, M. Coskun, C. Soendergaard, M. Salem, and O. H. Nielsen, "Inflammatory pathways of importance for management of inflammatory bowel disease," World Journal of Gastroenterology, vol. 20, no. 1, pp. 64-77, 2014.

[110] C. Becker-Pauly and S. Rose-John, “TNF $\alpha$ cleavage beyond TACE/ADAM17: matrix metalloproteinase 13 is a potential therapeutic target in sepsis and colitis," EMBO Molecular Medicine, vol. 5, no. 7, pp. 902-904, 2013.

[111] R. E. Vandenbroucke, E. Dejonckheere, F. van Hauwermeiren et al., "Matrix metalloproteinase 13 modulates intestinal epithelial barrier integrity in inflammatory diseases by activating TNF," EMBO Molecular Medicine, vol. 5, no. 7, pp. 932-948, 2013.

[112] J. H. Chidlow Jr., D. Shukla, M. B. Grisham, and C. G. Kevil, "Pathogenic angiogenesis in IBD and experimental colitis: new ideas and therapeutic avenues," American Journal of Physiology: Gastrointestinal and Liver Physiology, vol. 293, no. 1, pp. G5-G18, 2007.

[113] T. Kalebic, S. Garbisa, B. Glaser, and L. A. Liotta, "Basement membrane collagen: degradation by migrating endothelial cells," Science, vol. 221, no. 4607, pp. 281-283, 1983.

[114] J. M. Whitelock, A. D. Murdoch, R. V. Iozzo, and P. A. Underwood, "The degradation of human endothelial cell-derived perlecan and release of bound basic fibroblast growth factor by stromelysin, collagenase, plasmin, and heparanases," The Journal of Biological Chemistry, vol. 271, no. 17, pp. 10079-10086, 1996.

[115] Q. Yu and I. Stamenkovic, "Cell surface-localized matrix metalloproteinase- 9 proteolytically activates TGF- $\beta$ and promotes tumor invasion and angiogenesis," Genes and Development, vol. 14, no. 2, pp. 163-176, 2000.

[116] M. D’Angelo, D. P. Sarment, P. C. Billings, and M. Pacifici, "Activation of transforming growth factor $\beta$ in chondrocytes undergoing endochondral ossification," Journal of Bone and Mineral Research, vol. 16, no. 12, pp. 2339-2347, 2001.

[117] D. Mu, S. Cambier, L. Fjellbirkeland et al., "The integrin $\alpha \nu \beta 8$ mediates epithelial homeostasis through MT1-MMPdependent activation of TGF- $\beta 1$," The Journal of Cell Biology, vol. 157, no. 3, pp. 493-507, 2002.

[118] R. Heljasvaara, P. Nyberg, J. Luostarinen et al., "Generation of biologically active endostatin fragments from human collagen XVIII by distinct matrix metalloproteases," Experimental Cell Research, vol. 307, no. 2, pp. 292-304, 2005.

[119] X. Deng, G. Tolstanova, T. Khomenko et al., "Mesalamine restores angiogenic balance in experimental ulcerative colitis by reducing expression of endostatin and angiostatin: novel molecular mechanism for therapeutic action of mesalamine," The Journal of Pharmacology and Experimental Therapeutics, vol. 331, no. 3, pp. 1071-1078, 2009.

[120] J. H. Chidlow Jr., W. Langston, J. J. M. Greer et al., "Differential angiogenic regulation of experimental colitis," The American Journal of Pathology, vol. 169, no. 6, pp. 2014-2030, 2006.

[121] S. Danese, M. Sans, C. de la Motte et al., "Angiogenesis as a novel component of inflammatory bowel disease pathogenesis," Gastroenterology, vol. 130, no. 7, pp. 2060-2073, 2006.

[122] F. Scaldaferri, S. Vetrano, M. Sans et al., "VEGF-A links angiogenesis and inflammation in inflammatory bowel disease pathogenesis," Gastroenterology, vol. 136, no. 2, pp. 585.e5595.e5, 2009.

[123] S. Danese, M. Sans, D. M. Spencer et al., "Angiogenesis blockade as a new therapeutic approach to experimental colitis," Gut, vol. 56 , no. 6, pp. 855-862, 2007. 
[124] G. Tolstanova, X. Deng, T. Khomenko et al., "Role of antiangiogenic factor endostatin in the pathogenesis of experimental ulcerative colitis," Life Sciences, vol. 88, no. 1-2, pp. 74-81, 2011.

[125] S. Lee, S. M. Jilan, G. V. Nikolova, D. Carpizo, and M. L. IruelaArispe, "Processing of VEGF-A by matrix metalloproteinases regulates bioavailability and vascular patterning in tumors," The Journal of Cell Biology, vol. 169, no. 4, pp. 681-691, 2005.

[126] G. Bergers, R. Brekken, G. McMahon et al., "Matrix metalloproteinase-9 triggers the angiogenic switch during carcinogenesis," Nature Cell Biology, vol. 2, no. 10, pp. 737-744, 2000.

[127] M. Matusiewicz, K. Neubauer, M. Mierzchala-Pasierb, A. Gamian, and M. Krzystek-Korpacka, "Matrix metalloproteinase-9: its interplay with angiogenic factors in inflammatory bowel diseases," Disease Markers, vol. 2014, Article ID 643645, 8 pages, 2014.

[128] S. Balzan, C. de Almeida Quadros, R. de Cleva, B. Zilberstein, and I. Cecconello, "Bacterial translocation: overview of mechanisms and clinical impact," Journal of Gastroenterology and Hepatology, vol. 22, no. 4, pp. 464-471, 2007.

[129] M. Ailenberg and M. V. Sefton, "Effect of a matrix metalloproteinase sequestering biomaterial on Caco-2 epithelial cell barrier integrity in vitro," Acta Biomaterialia, vol. 5, no. 6, pp. 1898-1904, 2009.

[130] E. Huet, B. Vallée, J. Delbé et al., "EMMPRIN modulates epithelial barrier function through a MMP-mediated occludin cleavage: implications in dry eye disease," The American Journal of Pathology, vol. 179, no. 3, pp. 1278-1286, 2011.

[131] R. E. Vandenbroucke, E. Dejonckheere, P. Van Lint et al., "Matrix metalloprotease 8-dependent extracellular matrix cleavage at the blood-CSF barrier contributes to lethality during systemic inflammatory diseases," Journal of Neuroscience, vol. 32, no. 29, pp. 9805-9816, 2012.

[132] P. Garg, A. Ravi, N. R. Patel et al., "Sitaraman, Matrix metalloproteinase-9 regulates MUC-2 expression through its effect on goblet cell differentiation," Gastroenterology, vol. 132, no. 5, pp. 1877-1889, 2007.

[133] T. Kinugasa, Y. Akagi, T. Yoshida et al., "Increased claudin-1 protein expression contributes to tumorigenesis in ulcerative colitis-associated colorectal cancer," Anticancer Research, vol. 30, no. 8, pp. 3181-3186, 2010.

[134] J. L. Pope, A. A. Bhat, A. Sharma et al., "Claudin-1 regulates intestinal epithelial homeostasis through the modulation of Notch-signalling," Gut, vol. 63, pp. 622-634, 2014.

[135] P. Garg, M. Rojas, A. Ravi et al., "Selective ablation of matrix metalloproteinase-2 exacerbates experimental colitis: contrasting role of gelatinases in the pathogenesis of colitis," Journal of Immunology, vol. 177, no. 6, pp. 4103-4112, 2006.

[136] D. M. Hayden, C. Forsyth, and A. Keshavarzian, "The role of matrix metalloproteinases in intestinal epithelial wound healing during normal and inflammatory states," Journal of Surgical Research, vol. 168, no. 2, pp. 315-324, 2011.

[137] M. Puthenedam, F. Wu, A. Shetye, A. Michaels, K.-J. Rhee, and J. H. Kwon, "Matrilysin-1 (MMP7) cleaves galectin-3 and inhibits wound healing in intestinal epithelial cells," Inflammatory Bowel Diseases, vol. 17, no. 1, pp. 260-267, 2011.

[138] G. Latella, G. Rogler, G. Bamias et al., "Results of the 4th scientific workshop of the ECCO (I): pathophysiology of intestinal fibrosis in IBD," Journal of Crohn's and Colitis, 2014.

[139] J. P. Burke, J. J. Mulsow, C. O’Keane, N. G. Docherty, R. W. G. Watson, and P. R. O'Connell, "Fibrogenesis in Crohn's disease,"
The American Journal of Gastroenterology, vol. 102, no. 2, pp. 439-448, 2007.

[140] A. Di Sabatino, C. L. Jackson, K. M. Pickard et al., "Transforming growth factor $\beta$ signalling and matrix metalloproteinases in the mucosa overlying Crohn's disease strictures," Gut, vol. 58, no. 6, pp. 777-789, 2009.

[141] C. Medina, M. J. Santos-Martinez, A. Santana et al., "Transforming growth factor-beta type 1 receptor (ALK5) and Smad proteins mediate TIMP-1 and collagen synthesis in experimental intestinal fibrosis," Journal of Pathology, vol. 224, no. 4, pp. 461472, 2011.

[142] B. San-Miguel, I. Crespo, N. A. Kretzmann et al., "Glutamine prevents fibrosis development in rats with colitis induced by 2,4,6-trinitrobenzene sulfonic acid," Journal of Nutrition, vol. 140, no. 6, pp. 1065-1071, 2010.

[143] A. Leonardi, R. Cortivo, I. Fregona, M. Plebani, A. G. Secchi, and G. Abatangelo, "Effects of Th2 cytokines on expression of collagen, MMP-1, and TIMP-1 in conjunctival fibroblasts," Investigative Ophthalmology \& Visual Science, vol. 44, no. 1, pp. 183-189, 2003.

[144] X. Zhou, H. Hu, M.-L. N. Huynh et al., "Mechanisms of tissue inhibitor of metalloproteinase 1 augmentation by IL-13 on TGF$\beta 1$-stimulated primary human fibroblasts," Journal of Allergy and Clinical Immunology, vol. 119, no. 6, pp. 1388-1397, 2007.

[145] J. R. Bailey, P. W. Bland, J. F. Tarlton et al., "IL-13 promotes collagen accumulation in Crohn's disease fibrosis by downregulation of fibroblast MMP synthesis: a role for innate lymphoid cells?" PLoS ONE, vol. 7, no. 12, Article ID e52332, 2012.

[146] M. Lukas, "Inflammatory bowel disease as a risk factor for colorectal cancer," Digestive Diseases, vol. 28, no. 4-5, pp. 619624, 2010.

[147] T. Jess, E. V. Loftus Jr., F. S. Velayos et al., "Risk of intestinal cancer in inflammatory bowel disease: a population-based study from olmsted county, Minnesota," Gastroenterology, vol. 130, no. 4, pp. 1039-1046, 2006.

[148] O. R. F. Mook, W. M. Frederiks, and C. J. F. Van Noorden, "The role of gelatinases in colorectal cancer progression and metastasis," Biochimica et Biophysica Acta: Reviews on Cancer, vol. 1705, no. 2, pp. 69-89, 2004.

[149] A. Z. Gimeno-García, A. Santana-Rodríguez, A. Jiménez et al., "Up-regulation of gelatinases in the colorectal adenomacarcinoma sequence," European Journal of Cancer, vol. 42, no. 18, pp. 3246-3252, 2006.

[150] S. H. Itzkowitz and X. Yio, "Inflammation and cancer, IV. Colorectal cancer in inflammatory bowel disease: the role of inflammation," The American Journal of Physiology: Gastrointestinal and Liver Physiology, vol. 287, no. 1, pp. G7-G17, 2004.

[151] P. Garg, D. Sarma, S. Jeppsson et al., "Matrix metalloproteinase9 functions as a tumor suppressor in colitis-associated cancer," Cancer Research, vol. 70, no. 2, pp. 792-801, 2010.

[152] P. Garg, S. Jeppsson, G. Dalmasso et al., "Notchl regulates the effects of matrix metalloproteinase- 9 on colitis-associated cancer in mice," Gastroenterology, vol. 141, no. 4, pp. 1381-1392, 2011.

[153] K. Shang, Y.-P. Bai, C. Wang et al., "Crucial involvement of tumor-associated neutrophils in the regulation of chronic colitis-associated carcinogenesis in mice," PLoS ONE, vol. 7, no. 12, Article ID e51848, 2012.

[154] K. Assi, J. Mills, D. Owen et al., "Integrin-linked kinase regulates cell proliferation and tumour growth in murine colitisassociated carcinogenesis," Gut, vol. 57, no. 7, pp. 931-940, 2008. 
[155] Y. J. Kim, K. S. Hong, J. W. Chung, J. H. Kim, and K. B. Hahm, "Prevention of colitis-associated carcinogenesis with infliximab," Cancer Prevention Research, vol. 3, no. 10, pp. 13141333, 2010.

[156] Y. J. Kim, J. S. Lee, K. S. Hong, J. W. Chung, J. H. Kim, and K. B. Hahm, "Novel application of proton pump inhibitor for the prevention of colitis-induced colorectal carcinogenesis beyond acid suppression," Cancer Prevention Research, vol. 3, no. 8, pp. 963-974, 2010.

[157] S. Setia, B. Nehru, and S. N. Sanyal, "The PI3K/Akt pathway in colitis associated colon cancer and its chemoprevention with celecoxib, a Cox-2 selective inhibitor," Biomedicine \& Pharmacotherapy, 2014.

[158] K. J. Newell, L. M. Matrisian, and D. K. Driman, "Matrilysin (matrix metalloproteinase-7) expression in ulcerative colitisrelated tumorigenesis," Molecular Carcinogenesis, vol. 34, no. 2, pp. 59-63, 2002.

[159] L. M. Coussens, B. Fingleton, and L. M. Matrisian, "Matrix metalloproteinase inhibitors and cancer: trials and tribulations," Science, vol. 295, no. 5564, pp. 2387-2392, 2002.

[160] C. M. Overall and C. López-Otín, "Strategies for MMP inhibition in cancer: innovations for the post-trial era," Nature Reviews Cancer, vol. 2, no. 9, pp. 657-672, 2002.

[161] J. Wang, S. O'Sullivan, S. Harmon et al., "Design of barbituratenitrate hybrids that inhibit MMP-9 activity and secretion," Journal of Medicinal Chemistry, vol. 55, no. 5, pp. 2154-2162, 2012.

[162] S. O’Sullivan, C. Medina, M. Ledwidge, M. W. Radomski, and J. F. Gilmer, "Nitric oxide-matrix metaloproteinase-9 interactions: biological and pharmacological significance: NO and MMP-9 interactions," Biochimica et Biophysica Acta: Molecular Cell Research, vol. 1843, no. 3, pp. 603-617, 2014.

[163] M. M. Heimesaat, I. R. Dunay, D. Fuchs et al., "Selective gelatinase blockage ameliorates acute DSS colitis," European Journal of Microbiology and Immunology, vol. 1, pp. 228-236, 2011.

[164] R. M. Claramunt, L. Bouissane, M. P. Cabildo et al., "Synthesis and biological evaluation of curcuminoid pyrazoles as new therapeutic agents in inflammatory bowel disease: effect on matrix metalloproteinases," Bioorganic and Medicinal Chemistry, vol. 17, no. 3, pp. 1290-1296, 2009.

[165] J. N. Gordon, J. D. Prothero, C. A. Thornton et al., “CC-10004 but not thalidomide or lenalidomide inhibits lamina propria mononuclear cell TNF- $\alpha$ and MMP-3 production in patients with inflammatory bowel disease," Journal of Crohn's and Colitis, vol. 3, no. 3, pp. 175-182, 2009.

[166] C. Daniel, H. H. Radeke, N. A. Sartory et al., "The new low calcemic vitamin D analog 22-ene-25-oxa-vitamin D prominently ameliorates Thelper cell type 1-mediated colitis in mice," Journal of Pharmacology and Experimental Therapeutics, vol. 319 , no. 2, pp. 622-631, 2006.

[167] M. Martinesi, C. Treves, A. G. Bonanomi et al., "Downregulation of adhesion molecules and matrix metalloproteinases by ZK 156979 in inflammatory bowel diseases," Clinical Immunology, vol. 136, no. 1, pp. 51-60, 2010.

[168] U. Zügel, A. Steinmeyer, C. Giesen, and K. Asadullah, "A novel immunosuppressive $1 \alpha, 25$-dihydroxyvitamin D3 analog with reduced hypercalcemic activity," Journal of Investigative Dermatology, vol. 119, no. 6, pp. 1434-1442, 2002.

[169] T. Nijenhuis, B. C. J. van der Eerden, U. Zügel et al., "The novel vitamin D analog ZK191784 as an intestine-specific vitamin D antagonist," The FASEB Journal, vol. 20, no. 12, pp. 2171-2173, 2006.

[170] U. G. Strauch, F. Obermeier, N. Grunwald et al., "Calcitriol analog ZK191784 ameliorates acute and chronic dextran sodium sulfate-induced colitis by modulation of intestinal dendritic cell numbers and phenotype," World Journal of Gastroenterology, vol. 13, no. 48, pp. 6529-6537, 2007.

[171] M. Martinesi, S. Ambrosini, C. Treves et al., "Role of vitamin $\mathrm{D}$ derivatives in intestinal tissue of patients with inflammatory bowel diseases," Journal of Crohn's and Colitis, vol. 8, no. 9, pp. 1062-1071, 2014.

[172] T.-Y. Huang, H.-C. Chu, Y.-L. Lin et al., "Minocycline attenuates experimental colitis in mice by blocking expression of inducible nitric oxide synthase and matrix metalloproteinases," Toxicology and Applied Pharmacology, vol. 237, no. 1, pp. 69-82, 2009.

[173] Y.-D. Wang and W. Wang, "Protective effect of ilomastat on trinitrobenzenesulfonic acid-induced ulcerative colitis in rats," World Journal of Gastroenterology, vol. 14, no. 37, pp. 5683-5688, 2008.

[174] Q. Gao, M. J. W. Meijer, U. G. Schlüter et al., "Infliximab treatment influences the serological expression of matrix metalloproteinase (MMP)-2 and -9 in Crohn's disease," Inflammatory Bowel Diseases, vol. 13, no. 6, pp. 693-702, 2007.

[175] A. Di Sabatino, U. Saarialho-Kere, M. G. Buckley et al., "Stromelysin-1 and macrophage metalloelastase expression in the intestinal mucosa of Crohn's disease patients treated with infliximab," European Journal of Gastroenterology \& Hepatology, vol. 21, no. 9, pp. 1049-1055, 2009.

[176] M. J. Meijer, M. A. C. Mieremet-Ooms, W. van Duijn et al., "Effect of the anti-tumor necrosis factor- $\alpha$ antibody infliximab on the ex vivo mucosal matrix metalloproteinase-proteolytic phenotype in inflammatory bowel disease," Inflammatory Bowel Diseases, vol. 13, no. 2, pp. 200-210, 2007.

[177] L. Mäkitalo, T. Sipponen, P. Kärkkäinen, K.-L. Kolho, and U. Saarialho-Kere, "Changes in matrix metalloproteinase (MMP) and tissue inhibitors of metalloproteinases (TIMP) expression profile in Crohn's disease after immunosuppressive treatment correlate with histological score and calprotectin values," International Journal of Colorectal Disease, vol. 24, no. 10, pp. 11571167, 2009.

[178] L. Mäkitalo, H. Rintamäki, T. Tervahartiala, T. Sorsa, and K.-L. Kolho, "Serum MMPs 7-9 and their inhibitors during glucocorticoid and anti-TNF- $\alpha$ therapy in pediatric inflammatory bowel disease," Scandinavian Journal of Gastroenterology, vol. 47, no. 7, pp. 785-794, 2012.

[179] M. de Bruyn, K. Machiels, J. Vandooren et al., "Infliximab restores the dysfunctional matrix remodeling protein and growth factor gene expression in patients with inflammatory bowel disease," Inflammatory Bowel Diseases, vol. 20, no. 2, pp. 339-352, 2014.

[180] K. Kawabata, A. Murakami, and H. Ohigashi, "Auraptene decreases the activity of matrix metalloproteinases in dextran sulfate sodium-induced ulcerative colitis in ICR mice," Bioscience, Biotechnology and Biochemistry, vol. 70, no. 12, pp. 3062-3065, 2006.

[181] A. Witaicenis, A. C. Luchini, C. A. Hiruma-Lima et al., "Suppression of TNBS-induced colitis in rats by 4-methylesculetin, a natural coumarin: comparison with prednisolone and sulphasalazine," Chemico-Biological Interactions, vol. 195, no. 1, pp. 76-85, 2012.

[182] S. H. Lee, D. H. Sohn, X. Y. Jin, S. W. Kim, S. C. Choi, and G. S. Seo, "2l,4',6/-Tris(methoxymethoxy) chalcone protects against 
trinitrobenzene sulfonic acid-induced colitis and blocks tumor necrosis factor- $\alpha$-induced intestinal epithelial inflammation via heme oxygenase 1-dependent and independent pathways," Biochemical Pharmacology, vol. 74, no. 6, pp. 870-880, 2007.

[183] J. Epstein, G. Docena, T. T. MacDonald, and I. R. Sanderson, "Curcumin suppresses p38 mitogen-activated protein kinase activation, reduces IL- $1 \beta$ and matrix metalloproteinase- 3 and enhances IL-10 in the mucosa of children and adults with inflammatory bowel disease," British Journal of Nutrition, vol. 103, no. 6, pp. 824-832, 2010.

[184] R. Di Paola, E. Esposito, E. Mazzon et al., "Teupolioside, a phenylpropanoid glycosides of Ajuga reptans, biotechnologically produced by IRBN22 plant cell line, exerts beneficial effects on a rodent model of colitis," Biochemical Pharmacology, vol. 77, no. 5, pp. 845-857, 2009.

[185] E. Mazzon, E. Esposito, R. Di Paola et al., "Effects of verbascoside biotechnologically produced by Syringa vulgaris plant cell cultures in a rodent model of colitis," Naunyn-Schmiedeberg's Archives of Pharmacology, vol. 380, no. 1, pp. 79-94, 2009.

[186] G. Batist, F. Patenaude, P. Champagne et al., "Neovastat (Æ-941) in refractory renal cell carcinoma patients: report of a phase II trial with two dose levels," Annals of Oncology, vol. 13, no. 8, pp. 1259-1263, 2002.

[187] D. N. Sauder, J. DeKoven, P. Champagne, D. Croteau, and É. Dupont, "Neovastat (Æ-941), an inhibitor of angiogenesis: Randomized phase I/II clinical trial results in patients with plaque psoriasis," Journal of the American Academy of Dermatology, vol. 47 , no. 4 , pp. 535-541, 2002.

[188] J.-W. Mao, X.-M. He, H.-Y. Tang, and Y.-D. Wang, "Protective role of metalloproteinase inhibitor (AE-941) on ulcerative colitis in rats," World Journal of Gastroenterology, vol. 18, no. 47, pp. 7063-7069, 2012.

[189] D. K. Park and H.-J. Park, "Ethanol extract of Cordyceps militaris grown on germinated soybeans attenuates dextran-sodiumsulfate-(DSS) induced colitis by suppressing the expression of matrix metalloproteinases and inflammatory mediators," BioMed Research International, vol. 2013, Article ID 102918, 10 pages, 2013.

[190] M. A. A. Schepens, A. J. Schonewille, C. Vink et al., "Supplemental calcium attenuates the colitis-related increase in diarrhea, intestinal permeability, and extracellular matrix breakdown in HLA-B27 transgenic rats," Journal of Nutrition, vol. 139, no. 8, pp. 1525-1533, 2009.

[191] S. Cuzzocrea, E. Mazzon, I. Serraino et al., "Melatonin reduces dinitrobenzene sulfonic acid-induced colitis," Journal of Pineal Research, vol. 30, no. 1, pp. 1-12, 2001.

[192] E. Esposito, E. Mazzon, L. Riccardi, R. Caminiti, R. Meli, and S. Cuzzocrea, "Matrix metalloproteinase-9 and metalloproteinase-2 activity and expression is reduced by melatonin during experimental colitis," Journal of Pineal Research, vol. 45, no. 2, pp. 166-173, 2008.

[193] P. P. Trivedi and G. B. Jena, "Melatonin reduces ulcerative colitis-associated local and systemic damage in mice: investigation on possible mechanisms," Digestive Diseases and Sciences, vol. 58, no. 12, pp. 3460-3474, 2013.

[194] E. Talero, S. Garcia-Maurino, and V. Motilva, "Melatonin, autophagy and intestinal bowel disease," Current Pharmaceutical Design, vol. 20, no. 30, pp. 4816-4827, 2013.

[195] A. Berton, V. Rigot, E. Huet et al., "Involvement of fibronectin type II repeats in the efficient inhibition of gelatinases A and B by long-chain unsaturated fatty acids," Journal of Biological Chemistry, vol. 276, no. 23, pp. 20458-20465, 2001.
[196] C. Gravaghi, K. M. D. la Perle, P. Ogrodwski et al., "Cox-2 expression, PGE2 and cytokines production are inhibited by endogenously synthesized n-3 PUFAs in inflamed colon of fat1 mice," Journal of Nutritional Biochemistry, vol. 22, no. 4, pp. 360-365, 2011

[197] J. Y. Cho, S.-G. Chi, and H. S. Chun, "Oral administration of docosahexaenoic acid attenuates colitis induced by dextran sulfate sodium in mice," Molecular Nutrition and Food Research, vol. 55, no. 2, pp. 239-246, 2011.

[198] A. Annaházi, T. Molnár, K. Farkas et al., "Fecal MMP-9: a new noninvasive differential diagnostic and activity marker in ulcerative colitis," Inflammatory Bowel Diseases, vol. 19, no. 2, pp. 316-320, 2013.

[199] K. Farkas, Z. Sarodi, A. Bálint et al., "The diagnostic value of a new fecal marker matrix metalloprotease- 9 in different types of inflammatory bowel diseases," Journal of Crohn's and Colitis, vol. 8, pp. S111-S112, 2014.

[200] A. Balint, M. Szucs, K. Farkas et al., "P112 The triggering role of Clostridium difficile infection in the relapse of IBD and the clinical utility of fecal calprotectin and matrix-metalloproteinase- 9 in case of Clostridium-induced relapse," Journal of Crohn's and Colitis, vol. 8, pp. S108-S109, 2014.

[201] P. Devarajan, "Neutrophil gelatinase-associated lipocalin (NGAL): a new marker of kidney disease," Scandinavian Journal of Clinical and Laboratory Investigation, vol. 68, no. 241, pp. 89-94, 2008.

[202] M. de Bruyn, I. Arijs, W. J. Wollants et al., "Neutrophil gelatinase B-associated lipocalin and matrix metalloproteinase- 9 complex as a surrogate serum marker of mucosal healing in ulcerative colitis," Inflammatory Bowel Diseases, vol. 20, no. 7, pp. 11981207, 2014.

[203] M. Piekkala, J. Hagström, M. Tanskanen, R. Rintala, C. Haglund, and K.-L. Kolho, "Low trypsinogen-1 expression in pediatric ulcerative colitis patients who undergo surgery," World Journal of Gastroenterology, vol. 19, no. 21, pp. 3272-3280, 2013.

[204] M. A. Manfredi, D. Zurakowski, P. A. Rufo, T. R. Walker, V. L. Fox, and M. A. Moses, "Increased incidence of urinary matrix metalloproteinases as predictors of disease in pediatric patients with inflammatory bowel disease," Inflammatory Bowel Diseases, vol. 14, no. 8, pp. 1091-1096, 2008.

[205] A. Kofla-Dłubacz, M. Matusiewicz, E. Krzesiek, L. Noga, and B. Iwańczak, "Metalloproteinase- 3 and -9 as novel markers in the evaluation of ulcerative colitis activity in children," Advances in Clinical and Experimental Medicine, vol. 23, no. 1, pp. 103-110, 2014.

[206] B. Kabakchiev, D. Turner, J. Hyams et al., "Gene expression changes associated with resistance to intravenous corticosteroid therapy in children with severe ulcerative colitis," PLOS ONE, vol. 5, no. 9, Article ID e13085, 2010.

[207] F. Sipos, O. Galamb, B. Wichmann et al., "Peripheral blood based discrimination of ulcerative colitis and Crohn's disease from non-IBD colitis by genome-wide gene expression profiling," Disease Markers, vol. 30, no. 1, pp. 1-17, 2011.

[208] W. A. Faubion, J. G. Fletcher, S. O’Byrne et al., "EMerging BiomARKers in Inflammatory Bowel Disease (EMBARK) study identifies fecal calprotectin, serum MMP9, and serum IL-22 as a novel combination of biomarkers for Crohn's disease activity: role of cross-sectional imaging," American Journal of Gastroenterology, vol. 109, no. 5, p. 780, 2014.

[209] H. Yamaguchi, K. Suzuki, M. Nagata et al., "Irsogladine maleate ameliorates infl ammation and fi brosis in mice with chronic 
colitis induced by dextran sulfate sodium," Medical Molecular Morphology, vol. 45, no. 3, pp. 140-151, 2012.

[210] P. P. Trivedi and G. B. Jena, "Role of $\alpha$-lipoic acid in dextran sulfate sodium-induced ulcerative colitis in mice: studies on inflammation, oxidative stress, DNA damage and fibrosis," Food and Chemical Toxicology, vol. 59, pp. 339-355, 2013. 


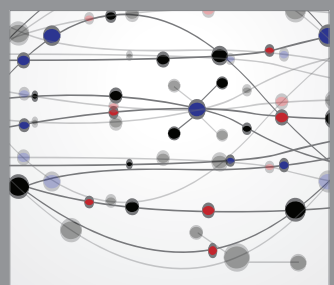

The Scientific World Journal
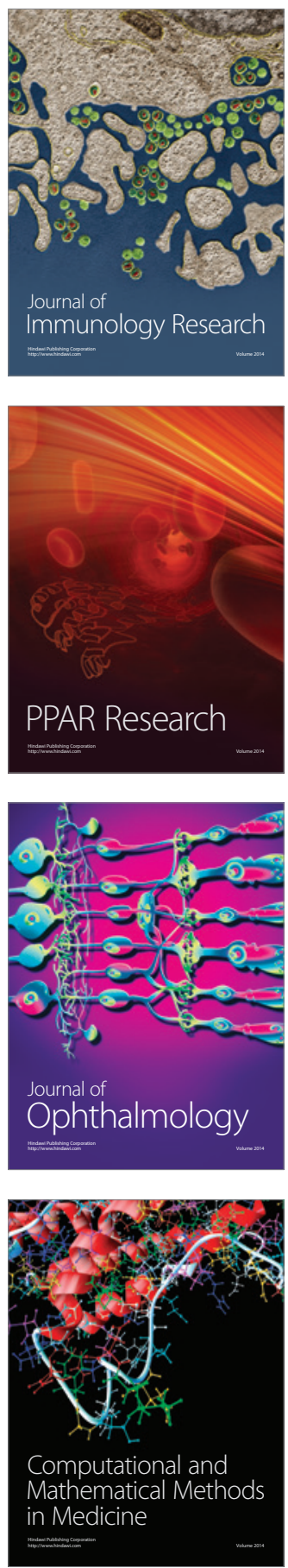

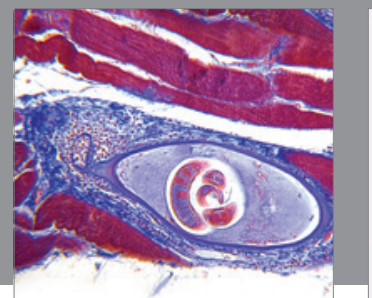

Gastroenterology

Research and Practice
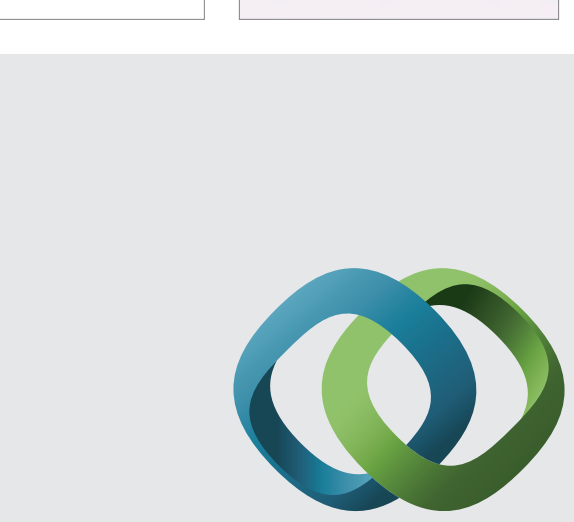

\section{Hindawi}

Submit your manuscripts at

http://www.hindawi.com
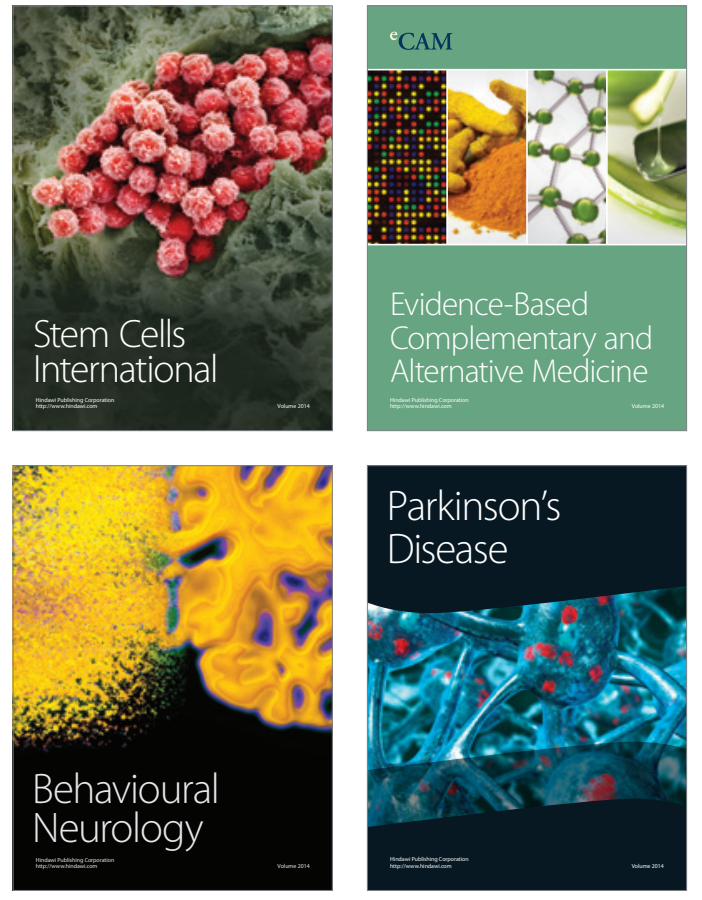
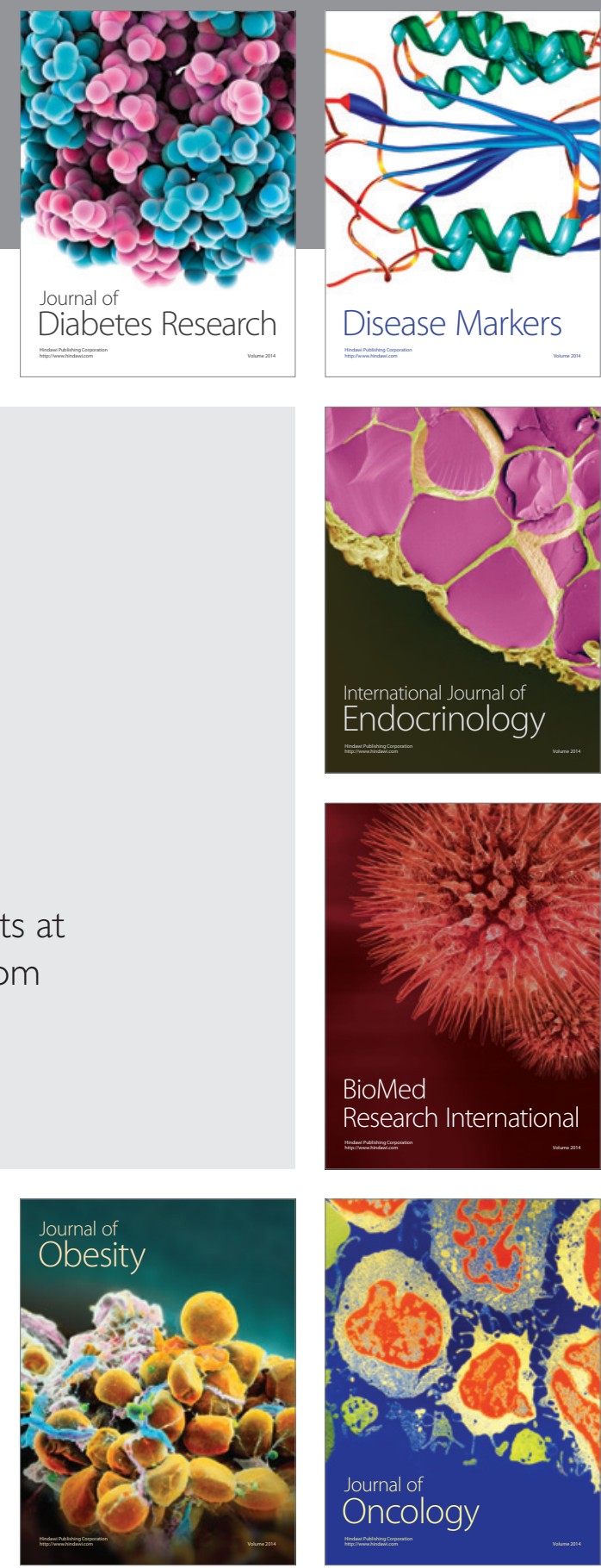

Disease Markers
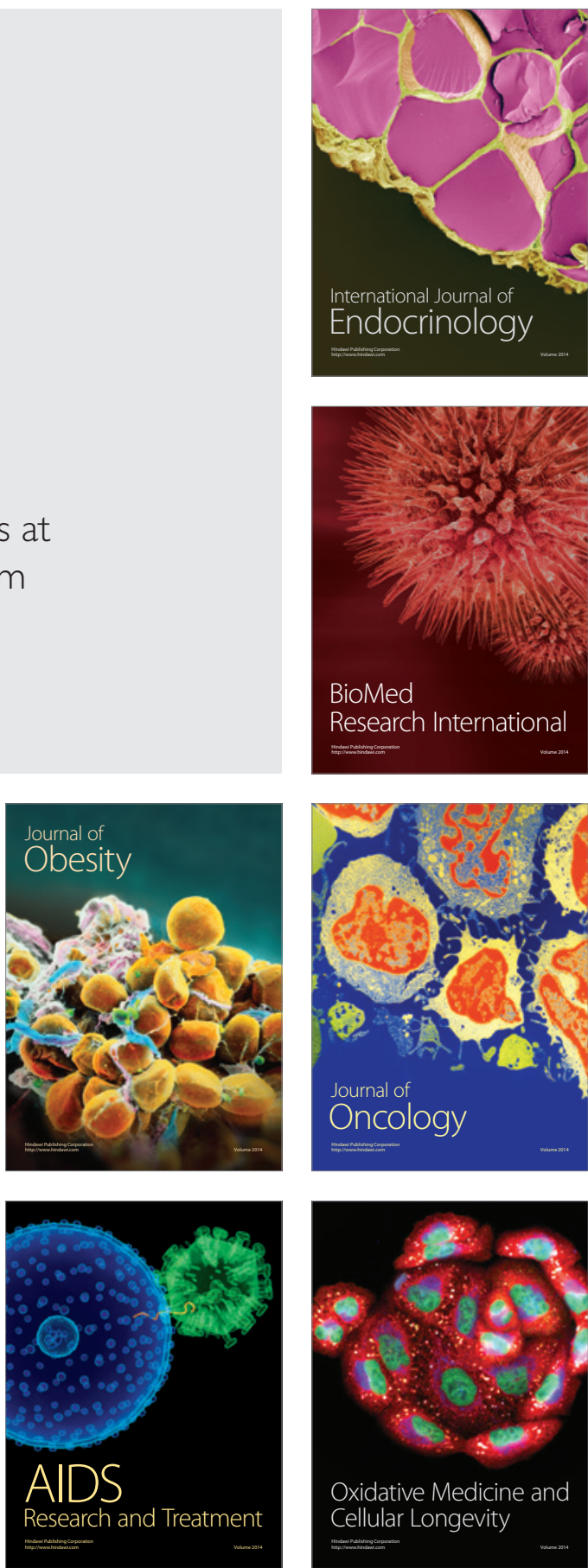